\title{
La structure multidimensionnelle des goûts
}

Une échelle de légitimité culturelle fondée sur les interactions entre diplôme, âge et sexe

The multidimensional structure of taste. A cultural legitimacy based on interactions between education, age, and gender

\section{Camille Noûs, Nicolas Robette et Olivier Roueff}

\author{
(2) OpenEdition \\ Journals \\ Édition électronique \\ URL : https://journals.openedition.org/bssg/598 \\ DOI : $10.4000 /$ bssg.598 \\ ISSN : 2490-9424 \\ Éditeur \\ Presses universitaires de Vincennes \\ Référence électronique \\ Camille Noûs, Nicolas Robette et Olivier Roueff, «La structure multidimensionnelle des goûts », Biens \\ Symboliques / Symbolic Goods [En ligne], 8 | 2021, mis en ligne le 20 mai 2021, consulté le 23 juillet \\ 2021. URL : http://journals.openedition.org/bssg/598 ; DOI : https://doi.org/10.4000/bssg.598
}

Ce document a été généré automatiquement le 23 juillet 2021.

Biens Symboliques / Symbolic Goods 


\section{La structure multidimensionnelle des goûts}

Une échelle de légitimité culturelle fondée sur les interactions entre diplôme, âge et sexe

The multidimensional structure of taste. A cultural legitimacy based on interactions between education, age, and gender

Camille Noûs, Nicolas Robette et Olivier Roueff

Fig. 1

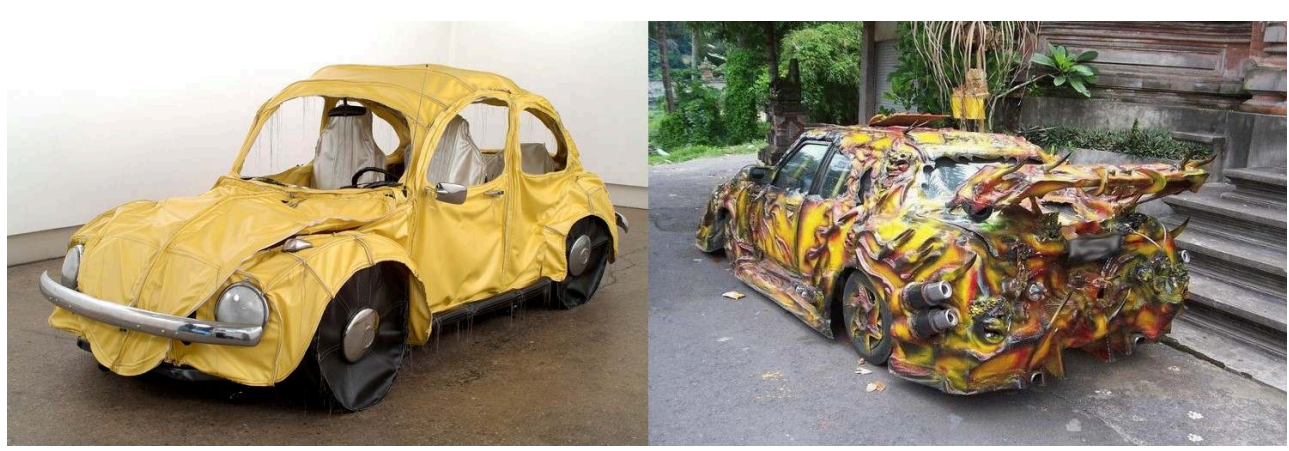

Sources : À gauche : Margarita Cabrera, Voco (Yellow), 2004, photo libre de droits. À droite : Photo publiée sans titre et sans auteur le 18 février 2010 sur Ze Jacky Touch

1 La notion de légitimité culturelle a connu, depuis ses premières formulations dans les années 1960 (Bourdieu \& Passeron 1964), de nombreuses déclinaisons et de nombreuses critiques. La parution de La Distinction (Bourdieu 1979) a marqué un jalon, son imposant et complexe dispositif empirique déployant l'ordonnancement des légitimités d'un large spectre de dimensions des styles de vie à l'échelle de l'espace social de la France métropolitaine - et notamment de sa triple structuration en fonction du volume, de la composition et de l'ancienneté relative des capitaux économiques et culturels. L'ouvrage achevait d'inscrire l'étude des rapports à la culture dans un cadre d'analyse qui dépassait le simple enregistrement des inégalités d'accès ou de la répartition sociale 
des goûts: la notion de légitimité culturelle emprunte au concept wébérien de légitimité (Weber 1971) pour appréhender comme dominante la culture associée aux classes supérieures, et plus spécifiquement à leurs fractions cultivées. L'échelle de légitimité culturelle est ainsi définie par l'homologie entre la hiérarchie symbolique des pratiques culturelles et la hiérarchie sociale des groupes sociaux qui les pratiquent. Ainsi, la culture légitime est celle qui non seulement est valorisée, bien que minoritaire, au sein des classes supérieures, mais aussi celle qui fait autorité bien au-delà de ce foyer de prescription : exerçant une "violence symbolique ", elle s'impose à tout l'ensemble social comme un étalon de référence, y compris sous la forme de l'adhésion maladroite (la «bonne volonté culturelle » des petits-bourgeois diplômés, dans La Distinction), de l'acquiescement poli, du rejet défensif, de la honte irrépressible - en bref, elle empêche l'indifférence et toute réaction même critique à son encontre doit être interprétée comme une reconnaissance de sa valeur sociale, de son poids symbolique, de sa force prescriptive.

2 À cette image d'une échelle uniformément prescriptive d'un bout à l'autre de l'espace social, Claude Grignon et Jean-Claude Passeron (1989) ont opposé l'ambivalence des pratiques populaires, éloignées du foyer bourgeois de la légitimité, tantôt disqualifiées comme mineures, voire dénuées de toute valeur culturelle, tantôt valorisées selon des ressorts symboliques autres, relativement autonomes des critères dominants. Cette ambivalence de la valeur des pratiques se redoublait dans l'ambivalence des points de vue savants, partagés entre le misérabilisme (qui ne voit dans les cultures populaires que leur écart à la culture légitime, leur dénuement symbolique) et le populisme (qui n'y voit que l'autonomie d'un rapport alternatif aux valeurs et aux biens symboliques, l'enchantement d'une culture populaire authentique). Et cette ambivalence des points de vue se traduit en partie dans les possibilités respectives des méthodologies d'enquête. Le traitement statistique de grands corpus de données relatives aux pratiques et aux goûts culturels de la population de la France métropolitaine fait surtout apparaître l'éloignement relatif des enquêtée's vis-à-vis des items proposés par le questionnaire, c'est-à-dire vis-à-vis de « la culture » en un sens qui ne peut que faire la part belle à ses définitions légitimistes: le poids statistique de la toute petite minorité des classes dominantes constituant le foyer de prescription symbolique dominant s'en trouve majoré, et l'immense majorité populaire s'en trouve essentiellement appréhendée en creux, comme non ou faiblement pratiquante. À l'inverse, l'enquête ethnographique explorant intensivement les valeurs et pratiques d'une population circonscrite insiste presque mécaniquement, du fait de la saturation des observations qualitatives effectuées dans un environnement relativement homogène, sur la spécificité de ce dernier, la manière dont ses ressorts alternatifs échappent à l'emprise de ce qui se trouve plus loin de l'observation, même quand ce plus loin s'avère aussi plus haut socialement.

3 Ces questionnements sont désormais bien connus et, bon an mal an, intégrés à un nombre croissant de dispositifs d'enquête - ethnographies des rapports de pouvoir centrés sur le capital culturel (Mauger, Poliak, Pudal 2010; Serre 2012), enquêtes statistiques sur des univers de pratiques spécifiques (pour ne citer que quelques-uns : Baudelot, Cartier, Detrez 1999 ; Coulangeon 2003 ; Duval 2016). À notre connaissance, depuis La Distinction (Bourdieu 1979), aucune analyse quantitative de la légitimité culturelle n'a été menée pour la France métropolitaine ${ }^{1}$ et pour plusieurs pratiques culturelles étudiées ensemble ${ }^{2}$. Nous avons montré dans un article précédent (Robette 
\& Roueff 2017), à partir de l'enquête Pratiques culturelles des Français menée en 2008 par le Département des études, de la prospective et des statistiques du ministère de la Culture (PCF 2008) ${ }^{3}$, qu'il était possible, sinon de tenir entièrement compte des autonomies relatives éloignées de la culture dominante, au moins d'établir, d'une part, que l'échelle de légitimité ordonne bien la distribution des goûts dans l'ensemble de l'espace social, y compris au sein des classes populaires, et, d'autre part, qu'un questionnaire "légitimiste » traité par une méthode d'analyse des correspondances surdimensionnant le poids des petits effectifs (donc de la culture légitime) n'empêchait pas d'observer des indices de l'existence d'univers symboliques populaires relativement autonomes - sans qu'il soit possible toutefois de trancher entre une explication en termes d'incompétence (faible maîtrise des classements légitimes), d'indifférence (une manière d'échapper aux effets de légitimité) ou d'autonomie relative (des principes alternatifs de hiérarchisation culturelle spécifiques aux classes populaires).

Pour autant, les analyses effectuées pour ce précédent article ont fait ressurgir un questionnement laissé en jachère au plan de la statistique empirique: l'échelle de légitimité culturelle étant établie par l'homologie entre l'ordonnancement des goûts et celui des groupes sociaux, de quel espace social est-il question? Enquêtant sur la force prescriptive de la culture des classes dominantes, notre analyse appréhendait ainsi l'espace social en termes, essentiellement, de distribution des capitaux économiques et culturels à partir des indicateurs de catégories socioprofessionnelles et de diplômes. Pourtant il est désormais établi que les goûts culturels répondent simultanément à d'autres logiques de différenciation, en particulier aux rapports d'âge et aux rapports de sexe (Bennett, Savage, Silva, Warde, Gayo-Cal, Wright 2009; Christin 2012; Coulangeon 2003; Donnat 2005, 2011 ; Detrez 2011; Octobre 2011; Roose, van Eijck, Lievens 2012 ; Albenga et al. 2014). D'autres travaux ont abordé cette question en allant jusqu'à opposer aux positions de classe d'autres facteurs structurants (tels que le diplôme, l'âge, le sexe...) afin d'évaluer leurs poids respectifs dans l'ordonnancement des goûts et des légitimités. Certains estiment que la puissance explicative des rapports de classe dans la formation des goûts serait théoriquement surévaluée (Macé \& Maigret 2005) ou tout au moins surinterprétée à partir d'écarts statistiques peu clivants (Fabiani 2007 ; Pedler \& Ethis 2001). D'autres font l'hypothèse qu'elle aurait été valable à l'époque de La Distinction mais serait désormais empiriquement affaiblie sous l'effet notamment de la massification scolaire et de l'hégémonie des industries culturelles productrices en particulier de " cultures juvéniles » (Pasquier 2005) ou de "dissonances culturelles " (Lahire 2004). L'hypothèse d'une montée de l'éclectisme culturel comme nouvelle norme légitime (Peterson \& Kern 1996; Peterson \& Simkus 1992) est ellemême traversée par ce débat: affaiblissement de l'ordonnancement social des goûts (Glévarec \& Pinet 2009) ou redéfinition du modèle légitime de la culture dominante avec le déclin de l'exclusivisme classique (Coulangeon 2003; Donnat 1994; Savage \& Gayo 2011) ${ }^{4}$ ?

Ces travaux ont souvent en commun de raisonner en procédant variable par variable pour observer les différences de goûts corrélées successivement aux indicateurs de classe, de sexe et d'âge. Ainsi des deux grandes enquêtes qui ont pris modèle sur $L a$ Distinction pour étudier les espaces des styles de vie en Grande-Bretagne (Bennett et al. 2009) et dans la ville d'Aalborg (Danemark) (Prieur et al. 2008). Comme l'a noté Julien Duval (2011), la première n'utilise l'analyse géométrique de données (AGD) que pour réduire l'information, sans exploiter réellement son caractère multidimensionnel : il est simplement constaté qu'à un premier axe opposant le snob au vulgaire, corrélé aux 
positions de classe (sans étude de la composition du capital), s'ajoutent un deuxième axe opposant l'établi à l'émergent, corrélé à l'âge, et un troisième axe opposant le privé au public, corrélé au sexe. De même, l'enquête sur Aalborg se contente de remarquer que les plus jeunes et les femmes se concentrent dans les régions de l'espace des goûts les plus corrélées à un fort volume de capital culturel. Quant aux travaux qui étudient l'articulation de ces variables, mentionnés plus haut, c'est exclusivement pour tester leurs poids respectifs, jouer l'une contre les autres, et non pour observer plus simplement l'effet de leurs interactions.

6 La construction statistique de l'échelle de légitimité culturelle repose, par définition, sur l'hypothèse d'une homologie entre les positions sociales et les prises de position culturelles: les goûts illégitimes sont corrélés aux positions sociales inférieures, les goûts légitimes aux positions sociales supérieures, ces corrélations étant relatives au sens où, par exemple, les goûts légitimes peuvent s'avérer minoritaires parmi les groupes de positions sociales supérieures et simplement plus souvent associées à ces derniers qu'aux autres groupes. Il s'agit bien d'associations et d'homologies. L'analyse statistique ne peut pas démontrer l'existence des homologies entre espace social et espace des goûts mais simplement constater leur ordonnancement conjoint - et elle peut par ailleurs démontrer l'existence d'homologies soit entre fractions de l'espace social, soit entre différents domaines de pratiques (voir sur ce point : Robette \& Roueff 2017). Elle ne peut non plus démontrer l'existence d'effets de légitimité au-delà de l'appui sur deux types d'indices. Le premier est, quand le questionnaire le permet, l'expression de dégoûts, par des membres de catégories dominantes, envers des modalités de goûts fortement appréciées par des catégories dominées. Ceci peut être interprété comme l'indice d'une quête de distinction, ou d'une tentative de produire des effets de légitimité. Avec le second, on peut montrer que les goûts fortement associés aux catégories dominantes polarisent l'ensemble de l'espace des goûts mais aussi, lorsqu'on réduit la focale, les espaces de goûts spécifiques à chaque groupe composant l'espace social, jusqu'aux plus dominés (Robette \& Roueff 2017).

7 Il s'agit donc pour nous de construire empiriquement, à partir de l'enquête PCF 2008 représentative de la population française de plus de 15 ans, l'espace social servant à ordonner les goûts sur une échelle de légitimité en utilisant des indicateurs de position au sein de plusieurs rapports sociaux de pouvoir, en l'occurrence la classe, l'âge et le sexe. Dit autrement, est-il possible de tenir compte statistiquement de la pluralité et de l'intersectionnalité ${ }^{5}$ des rapports sociaux de pouvoir (classe, race, sexe, selon le triptyque routinier, mais aussi âge, territoire, santé, etc.) que de nombreuses enquêtes ethnographiques (par exemple : Skeggs 1997 ; Khan 2011 ; Avril 2014 ; Le Renard 2019) ont désormais établies à l'échelle des individus et des groupes sociaux? Ou encore : comment analyser les corrélations entre les variables de position sociale sans tomber dans le piège improductif de la hiérarchisation des effets mais plutôt en termes d'interactions? Notre hypothèse est que la légitimité culturelle se définit au croisement de l'ensemble des rapports sociaux de pouvoir, réduits ici aux trois indicateurs statistiques disponibles du diplôme, de l'âge et du sexe. Non seulement le « snob » (bourgeois lettré), «l'établi » (ancien, classique) et l'« élégant» (féminin, par opposition au grossier, masculin ${ }^{6}$ ) fonctionnent ensemble pour définir le critère du bon goût, si bien que ce dernier est plus souvent associé simultanément aux diplômée's du supérieur, aux personnes âgées et aux femmes, mais l'effet combiné de ces principes de distinction diffère d'un bout à l'autre de l'échelle de légitimité, si bien que le moins 
légitime est quant à lui plus souvent associé aux peu diplômé·e·s et, à nouveau, aux personnes âgées et aux femmes.

Nous commencerons par exposer le problème en observant la forme de l'échelle de légitimité telle qu'elle peut être construite à partir de l'homologie entre la projection factorielle des positions sociales et celle des goûts en matière de lecture, de cinéma, de musique et de télévision (1a). Nous développerons ainsi deux caractéristiques de cette échelle de légitimité : d'une part, celle-ci est non seulement sensible à l'axe associé aux capitaux économiques et culturels (axe auquel elle est généralement identifiée), mais elle l'est aussi à l'axe associé aux variables d'âge et de sexe; d'autre part, cette échelle n'est pas linéaire: elle n'a pas la forme d'une droite, même diagonale sur l'espace factoriel, mais celle d'un "U aplati » (1b). Autrement dit, les « effets» des variables diffèrent selon les modalités des autres variables de position avec lesquelles elles interagissent. Le problème établi et circonscrit, nous envisagerons ensuite trois manières d'en affiner les attendus, en soulignant les apports et les limites de chacune. Une classification ascendante hiérarchique autorise d'abord à préciser les configurations de modalités les plus corrélées entre elles. L'attention fine portée à la triple association des goûts au diplôme, à l'âge et au sexe permet alors, en particulier, d'éviter les interprétations erronées d'une telle typologie - celles qui verraient des goûts «moyens » à la place des goûts les plus légitimes (2a). L'échelle de légitimité culturelle identifiée auparavant et sa forme courbe en sortent renforcées, et l'intérêt d'étudier l'effet d'une variable par opposition aux effets des autres variables s'en trouve affaiblie, au profit de l'étude de leurs interactions. Ainsi, la projection, sur l'espace des goûts, de variables synthétiques combinant les modalités de diplôme, d'âge et de sexe permet de décrire les interactions entre ces trois variables et de montrer pourquoi elles forment une courbe, c'est-à-dire pourquoi elles n'agissent pas dans le même sens en haut, au milieu et en bas de l'échelle de légitimité (2b).

\section{Une échelle courbe, sensible aux capitaux économiques et culturels comme à l'âge et au sexe}

\subsection{Principes de construction}

9 Peu de travaux s'emploient à construire empiriquement l'échelle de légitimité culturelle et, quand ils le font, c'est à partir d'indicateurs et de techniques de calcul très différents (Robette \& Roueff 2014). Le principe en est pourtant simple : par définition, l'échelle consiste en l'ordonnancement des indicateurs de styles de vie (ici, de goûts culturels) en fonction des indicateurs de position sociale (Bourdieu 1979). Parmi les démarches disponibles, nous privilégions les méthodes d'analyse géométrique de données car elles permettent de mobiliser simultanément plusieurs indicateurs de goûts et de positions ${ }^{7}$, minorant ainsi les effets appauvrissants et, parfois, divergents de choix sélectifs (Robette \& Roueff 2014). Parmi ces méthodes, nous utilisons l'analyse factorielle de tableaux multiples (AFM) mise au point par Brigitte Escofier et Jérôme Pagès (2008) car nous traitons des données sur les goûts en matière de cinéma, de lecture, de musique et de télévision, soit les domaines les mieux renseignés au sein des données de l'enquête Pratiques culturelles des Français réalisée en 2008 (PCF 2008) par le Département des études, de la prospective et des statistiques du ministère de la Culture ${ }^{8}$. Les variables actives sont par principe les variables de goût: il s'agit d'observer leur 
ordonnancement indépendamment des propriétés sociales, puis de projeter en supplémentaires les variables indiquant ces dernières pour étudier la manière dont elles se «superposent" aux premières. L'AFM permet alors d'équilibrer les contributions des différents groupes de variables (correspondant chacun aux quatre domaines de goûts précédemment cités) à la structuration de l'espace factoriel, afin qu'un domaine particulièrement clivé ou doté d'une plus grande quantité de variables et de modalités ne pèse pas plus que les autres de manière artefactuelle.

Analyse factorielle de tableaux multiples (AFM) et analyse spécifique

Techniquement, l'AFM revient ici à faire des Analyses de Correspondances Multiples (ACM) séparées pour chaque domaine, à rassembler les coordonnées des individus sur les axes de ces ACM et à réaliser une Analyse en Composantes Principales (ACP) à partir de ces coordonnées en les pondérant par la variance du premier axe de leur domaine. L'AFM rend ainsi compte des liaisons à l'intérieur de chaque domaine et des liaisons entre domaines. Il s'agit donc d'une manière de superposer les quatre espaces gustatifs mais par un calcul statistique prévu à cet effet plutôt qu'à la main ou par une simple ACM indifférente aux équilibres entre domaines9. Par ailleurs, toutes les analyses factorielles réalisées sont "spécifiques ». Cela permet de rendre passives certaines modalités de variables actives afin qu'elles ne contribuent pas à la construction de l'espace. C'est par exemple le cas des modalités peu intéressantes (" autre » ou " non renseigné ») ou à faible effectif, qui, autrement, pèseraient inutilement sur la construction de l'espace (Le Roux \& Rouanet 2004). Nous avons utilisé le logiciel R et le package GDAtools qui dispose entre autres de tous les outils d'analyse géométrique mobilisés ici. 
Fig. 2. L'espace des goûts en matière de cinéma, de lecture, de télévision et de musique (AFM)

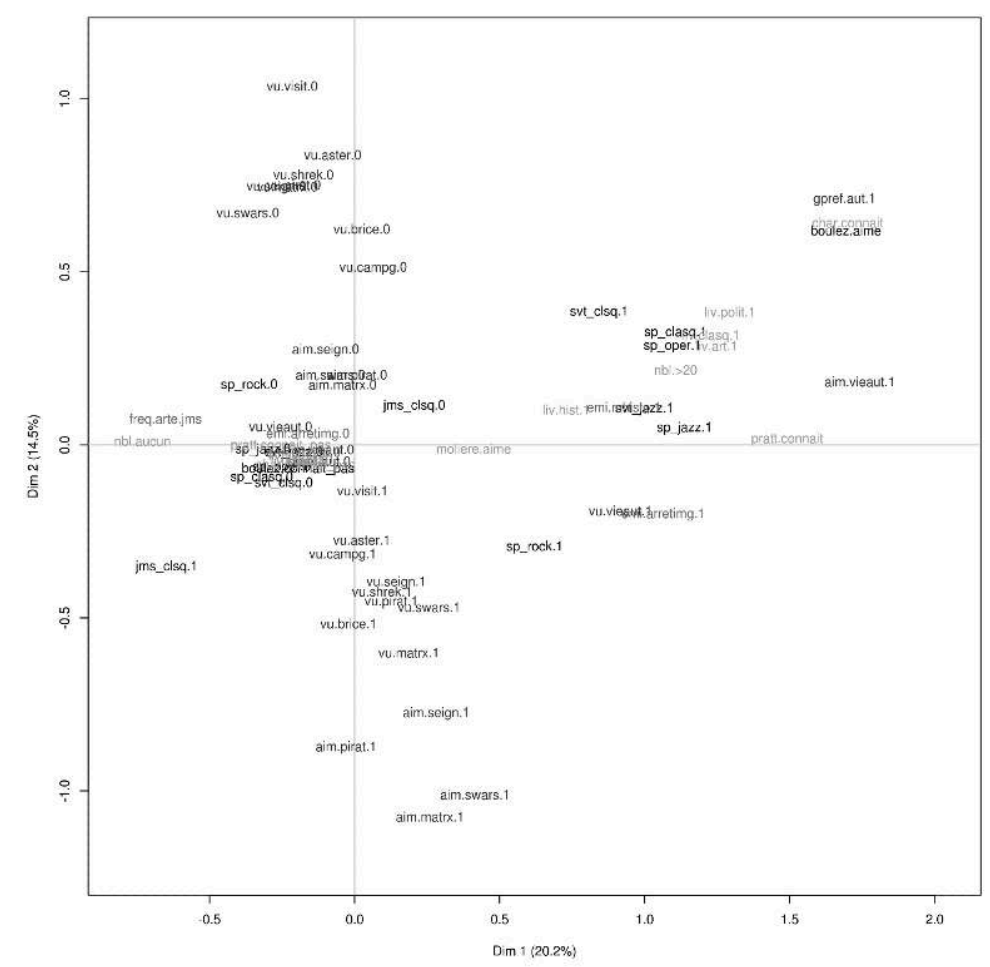

Note : Afin de favoriser la lecture, seules les modalités les plus associées aux axes 1 et/ou 2 sont représentées

Source: Pratiques culturelles des Français 2008 (DEPS). Les libellés complets et les abrégés correspondants sont disponibles ici (Robette \& Roueff 2017, Annexe 1)

10 L'analyse détaillée de cet espace des goûts a déjà été publiée accompagnée de justifications plus substantielles des choix de méthode effectués et de représentations graphiques plus lisibles (Robette \& Roueff 2017). Nous nous permettons d'y renvoyer car, ici, il s'agit seulement de faire apparaitre rapidement les principaux facteurs de différenciation ainsi que la forme globale de la dispersion des modalités de goûts et de propriétés sociales, avant de focaliser notre attention sur l'étude des interactions constitutives de l'échelle de légitimité.

11 L'axe 1 oppose les non pratiques (par exemple "aucun livre lu») et les pratiques les plus diffusées (regarder le feuilleton Plus belle la vie) aux pratiques les plus ésotériques (par exemple lire le quotidien Le Monde ou écouter la musique de Pierre Boulez). L'axe 2 oppose les pratiques émergentes (lire de la bande dessinée ou regarder la série Prison Break) et/ou masculines (les films d'action comme genre cinématographique préféré) aux pratiques établies (regarder la chaîne France 3) et/ou féminines (préférer la musique classique ou les livres des Éditions Harlequin ${ }^{10}$ ). Ces qualifications sont bien sûr relationnelles : la BD est "plus émergente » (ou plus récemment intégrée au patrimoine culturel) que le roman, les films d'action «plus masculins » que les comédies sentimentales, etc. ${ }^{11}$ Elles ne sont par ailleurs pas exclusives: les films d'action sont aussi "juvéniles » et la musique classique aussi «bourgeoise » - c'est précisément tout notre propos que d'insister sur ce constat, et il s'agit ici simplement de caractériser les axes de l'AFM en les illustrant par quelques modalités suggestives. 
Pour extraire l'échelle de légitimité culturelle, il suffit ensuite de projeter en supplémentaires, sur cet espace des goûts, les variables de position sociale (catégorie socioprofessionnelle, diplôme, revenu, âge, sexe, patrimoine) et d'observer leur ordonnancement (Figure 3) ${ }^{12}$.

Fig. 3. Projection en variables supplémentaires des modalités de position sur l'AFM des goûts en matière de télévision, de cinéma, de lecture et de musique

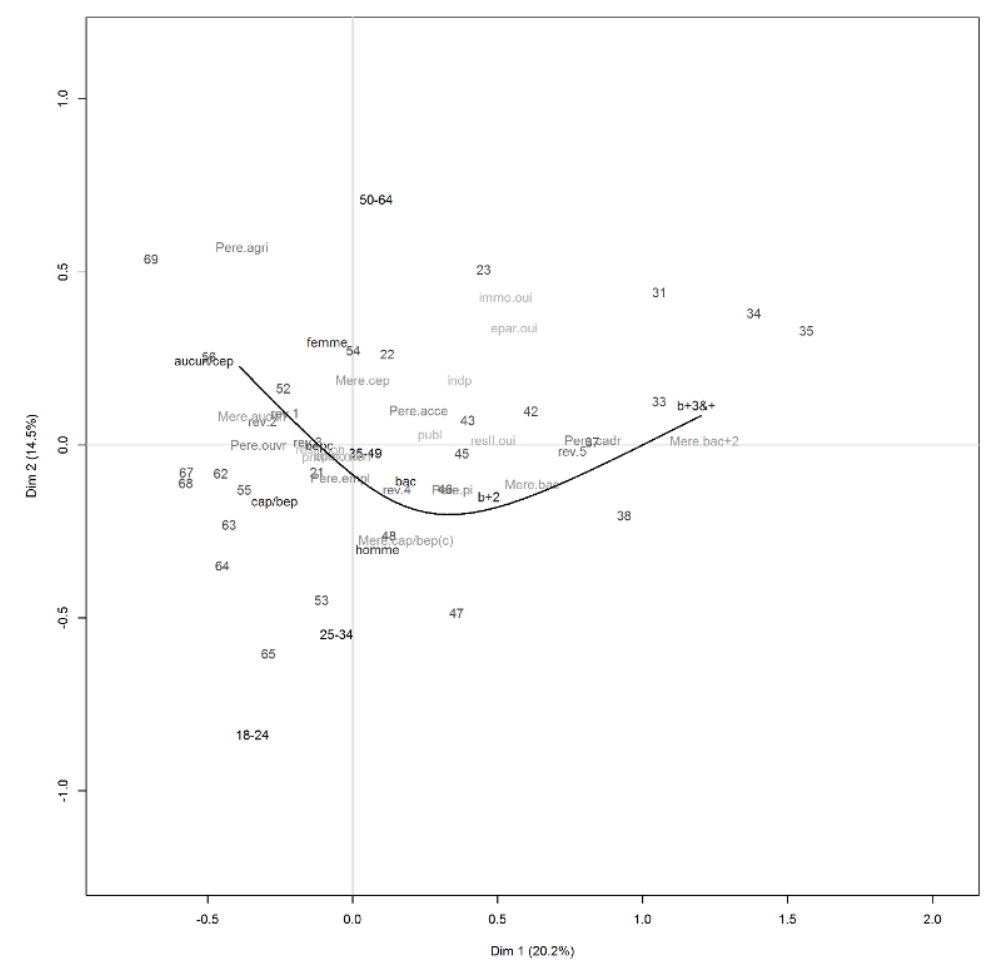

La courbe a été dessinée manuellement pour aider la visualisation de l'alignement « courbe » des modalités.

Source : Pratiques culturelles des Français 2008 (DEPS). Les catégories socioprofessionnelles en 24 postes sont notées par leur code à 2 chiffres ; figurent aussi le sexe, la tranche d'âge $(15-17$; 18-24 ; 25-34; 35-49; 50-64), le statut d'emploi ( publ » = emploi public ; « priv » = emploi privé ; «indp »= indépendant), le diplôme (« aucun/cep »; « cap/bep »; «bac »; «b+2 » = bac+2; «b+3\&+ » = bac+3 et plus), le revenu du ménage (noté « rev. » et suffixé par le quintile), le diplôme de la mère (« Mere. » suffixé par le niveau de diplôme), la profession du père (« Pere. » suffixé par la catégorie socioprofessionnelle en 6 postes), possession d'une résidence secondaire (« resll. » suffixé par oui / non), la possession d'un patrimoine immobilier (« immo. » suffixé par oui / non) et la possession d'épargne («epar » suffixé par oui / non). Voir https://sociologie.revues.org/3275 (annexe 1 de Robette \& Roueff 2017) pour plus de détails sur les modalités.

\subsection{Une courbe en $\mathrm{U}$ : interactions entre capitaux, âge et sexe}

L'habitude consiste à considérer l'axe 1 (en abscisse dans la fig. 3) des espaces factoriels de ce type comme une représentation de l'échelle de légitimité car il est essentiellement corrélé aux indicateurs de volume de capitaux économiques et culturels. Il s'agit de fait d'une bonne approximation comme l'atteste la figure 3. Il est cependant possible d'être plus précis en observant d'abord la répartition exacte des variables de position projetées en supplémentaires. Les capitaux économiques et culturels sont fortement corrélés à l'axe 1 , tandis que l'âge et le sexe le sont à l'axe $2^{13}$. Mais ils ne sont pas strictement alignés avec ces axes - ce qui s'avère peu surprenant: 
les capitaux économiques et culturels ne sont pas totalement indépendants de l'âge et du sexe. C'est plutôt l'effet de cette interaction sur la morphologie globale de l'espace qu'il vaut la peine d'étudier de plus près. En effet, toutes les variables de classe, assez strictement alignées les unes avec les autres, forment une courbe en " $U$ allongé » allant du nord-ouest au nord-est en passant par le sud du graphique ${ }^{14}$. De plus, ce sont les variables de capital culturel qui sont les plus dispersées le long de cette courbe. La distribution des catégories socioprofessionnelles étant sensible en particulier au sexe, on trouve traditionnellement, à grands traits, les secteurs professionnels féminisés en haut (employées, services aux particuliers, professions intermédiaires de la santé et du travail social, professeures des écoles...) et les secteurs professionnels masculinisés en bas (ingénieurs, ouvriers qualifiés et non qualifiés, techniciens et contremaîtres...). Mais, en suivant la courbe, on passe bien des ouvriers et employés non qualifiés aux ouvriers qualifiés, puis aux professions intermédiaires puis aux cadres.

$\mathrm{Si}$, fort de cette information, on observe l'espace des goûts (Figure 2), ce même «U aplati » apparait clairement. En suivant la courbe, on passe des "non pratiques » ainsi que des goûts les plus divulgués, les plus anciens et les plus féminins dans le quart nord-ouest, aux pratiques les plus intenses et les plus ésotériques dans le quart nordest, en passant par les pratiques ni vulgaires ni snobs, émergentes et masculines dans la moitié $\operatorname{sud}^{15}$. En bref, l'échelle dominante de légitimité culturelle, définie par l'homologie entre distribution du capital, notamment culturel, et distribution des goûts, consiste en une courbe en U sensible à la fois à l'axe des rapports de classe et à l'axe des rapports d'âge et de sexe. Ceci ne remet pas en cause les habitudes d'interprétation des distributions statistiques des goûts, identifiant l'échelle dominante de légitimité à l'axe 1 quand il s'agit d'analyses factorielles, ou au simple ordonnancement des goûts par des variables de position de classe. Au contraire, on confirme ici que ce sont là de bonnes approximations. Ce qu'apporte cet examen de l'échelle dominante de légitimité, c'est plutôt l'indice que cette dernière est composée aussi d'assignations de sexe et d'âge, sans que ces variables soient associées de manière strictement linéaire (ce qui serait par exemple le cas si la légitimité des goûts augmentait à la fois avec le niveau de diplôme et avec l'âge).

\section{De quel espace social l'espace des goûts est-il homologue?}

Le but des traitements suivants consiste, d'une part, à confirmer l'intérêt de considérer l'espace social homologue à l'ordonnancement des goûts comme constitué d'interactions entre diplôme, âge et sexe, et, d'autre part, à trouver des moyens statistiques de décrire plus finement ces interactions et, en particulier, leurs variations aux différents niveaux de l'échelle de légitimité. On ne retient dorénavant que le diplôme comme indicateur de position de classe pour trois raisons. D'une part, il s'agit de la variable de classe la plus discriminante et la plus corrélée à l'axe 1 (abscisse de la figure 3). D'autre part, les autres indicateurs de classe sont presque strictement alignés avec le diplôme. Enfin, l'objectif de l'analyse est d'établir l'existence et la forme d'interactions entre plusieurs rapports sociaux de pouvoir associées à la légitimité culturelle, tout en réservant l'exploration plus fine des modalités (comme l'étude des explications sociohistoriques de la multidimensionnalité de la légitimité culturelle) à une poursuite ultérieure de l'enquête. C'est pour les mêmes raisons qu'on ne 
s'interroge pas ici sur ce que signifie l'âge au simple sens de distance à l'année de naissance, qu'il indique une position dans le cycle de vie ou une appartenance générationnelle (Donnat 2011) : il nous suffit de montrer que les rapports sociaux d'âge interagissent avec ceux de classe et ceux de sexe.

\subsection{Une échelle enrichie par la classification (CAH) : l'action conjointe du diplôme, de l'âge et du sexe}

Le constat d'interactions entre âge, sexe et diplôme devrait se retrouver dans les résultats d'une classification ascendante hiérarchique (CAH), réalisée à partir des coordonnées individuelles sur les deux premiers axes. L'intérêt d'une telle méthode - si elle converge avec la précédente - est d'enrichir l'interprétation des différents échelons de l'échelle de légitimité, puisqu'elle agrège, au sein de chaque classe de la typologie, des configurations de modalités plus riches et plus précises que les simples agrégats visuels des figures 2 et 3 . L'examen visuel du dendrogramme ainsi que l'analyse des classes obtenues suggère une partition en six classes. On commence donc par projeter, sur le nuage des individus de l'AFM, les ellipses de concentration des six classes obtenues par la CAH (Figure 4).

Fig. 4. Projection des ellipses de concentration des clusters (CAH) sur l'AFM

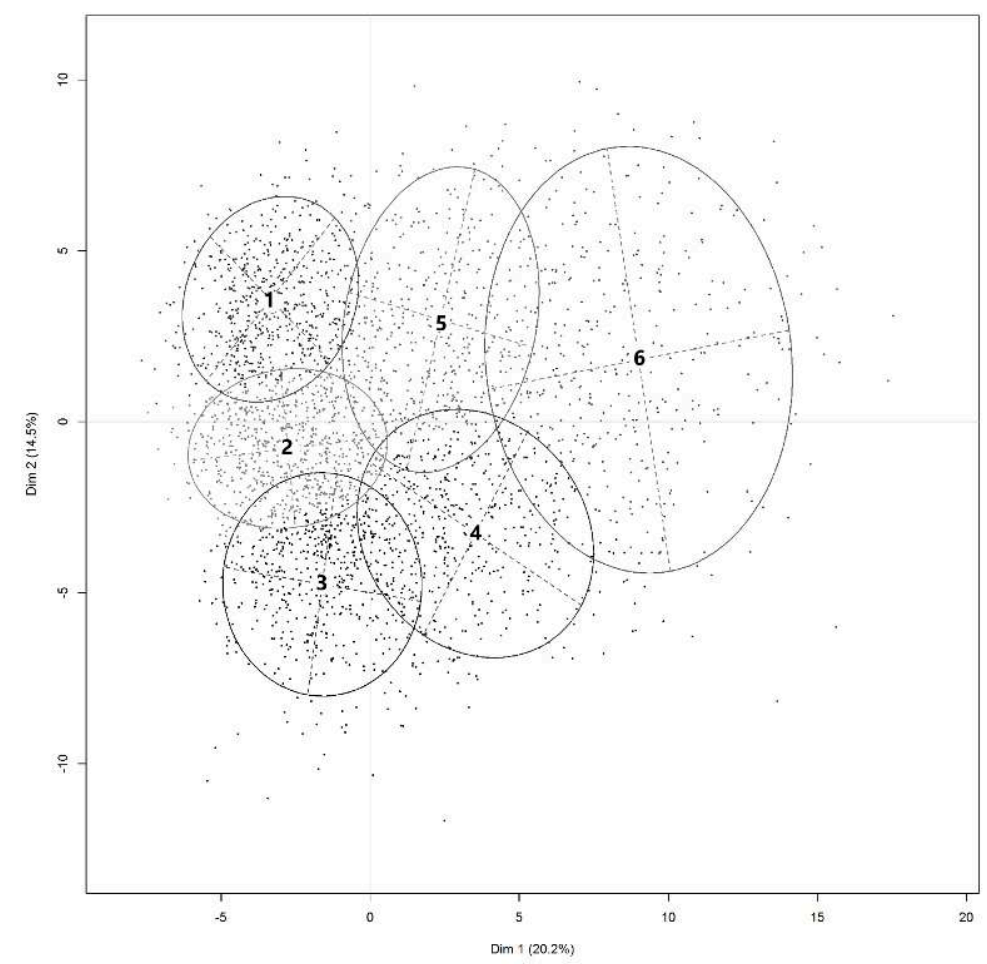

Source : Pratiques culturelles des Français 2008 (DEPS)

La lecture du graphique semble évidente a priori si l'on s'en tient à l'approximation de l'échelle de légitimité par l'axe 1. On aurait trois clusters populaires, l'un plus masculin et émergent (3), un autre d'âge moyen (2) et un dernier plus féminin et âgé (1), puis deux clusters intermédiaires, l'un masculin et émergent (4) et l'autre féminin et âgé (5) et, enfin, un cluster bourgeois, légèrement féminin et âgé (6). Les analyses précédentes 
doivent pourtant nous orienter sur une meilleure piste : ne retrouverait-on pas plutôt notre échelle de légitimité en U ? Avec le cluster 1 en "bas » de cette échelle (c'est-àdire au nord-ouest du graphique), puis le 2 et le 3, puis le 4 (au sud du graphique) et, enfin, deux variantes de la culture légitime avec les clusters 5 et 6 (au nord-est)?

Observons alors les modalités significativement corrélées à chaque cluster ${ }^{16}$. Le cluster 3 (Annexe 1, tableau 3) est d'abord défini par les goûts en matière de musique et de télévision et, dans une moindre mesure, de cinéma. On y trouve les plus fortes consommations de musique et de télévision, une fréquentation du cinéma comparativement importante sans être la plus forte (de 5 à 11 séances annuelles) et une pratique très faible de la lecture. Les goûts surreprésentés peuvent être décrits à la fois comme populaires, émergents et masculins - le rap et la musique électronique, les émissions grand public de $\mathrm{TF}^{17}$ et secondairement les marqueurs masculins que sont Stade $2^{18}$ et la série Prison Break, les films d'action et de science-fiction, ainsi que le rejet des comédies musicales et des films d'amour, un rapport au livre épisodique et concentré sur la BD. Ces trois qualifications sont homologues des propriétés sociales les plus associées au cluster, très homogènes: des hommes jeunes peu diplômés et ouvriers. C'est l'association entre le sexe et l'âge qui est la plus significative du fait que c'est là ce qui distingue ce pôle des autres pôles des classes populaires. La jeunesse, en particulier, explique probablement la fréquentation comparativement importante du cinéma (Duval 2011).

Le cluster 1 (Annexe 1, tableau 1) se caractérise en premier lieu par l'éloignement des pratiques culturelles, à proportion inverse de la fréquentation assidue de la télévision. Dans ce domaine, les goûts surreprésentés sont à la fois populaires, établis et féminins : les séries Les feux de l'amour ${ }^{19}$, Plus belle la vie ${ }^{20}$ et Dallas, les émissions Qui veut gagner des millions ? ${ }^{21}$, Des chiffres et des lettres ${ }^{22}$, Le plus grand cabaret du monde ${ }^{23}$ et TV shopping, le tout sur TF1 et France $3^{24}$. Le même profil ressort des autres domaines : films d'amour, variétés françaises, romans Harlequin ${ }^{25}$ et magazines people ou télé - avec de manière significative un rejet des films d'action et de science-fiction appréciés au pôle masculin et juvénile des classes populaires (soit le cluster 3). De fait, le cluster 1 représente le pôle féminin et âgé des classes populaires, même si l'association entre les variables de sexe et d'âge est moins uniforme qu'au sein du cluster 3 : on trouve aussi surreprésentés des hommes âgés et des femmes d'âge moyen.

Le cluster 2 (Annexe 1, tableau 2) est caractérisé par une forte fréquentation de la télévision et de la musique et par une faible fréquentation des livres et du cinéma. En matière télévisuelle, on retrouve les goûts populaires des clusters 1 et 3 sans les marqueurs de masculinité ou de féminité qui distinguaient ces derniers. En matière musicale, l'écoute est périphérique (en faisant autre chose) et concentrée sur les variétés internationales à la fois populaires et émergentes (par rapport aux variétés françaises). En matière de cinéma, les préférences vont aux comédies grand public soit l'univers du cinéma populaire là aussi dénué des marqueurs de masculinité ou de féminité des clusters 1 et 3 . Les goûts en matière de lecture font enfin apparaître les magazines people et télé, les romans Harlequin ainsi que les livres pratiques. Cet univers culturel peut être défini comme celui de la culture populaire la plus partagée, centrée sur l'offre la plus accessible matériellement et culturellement (télévision, radio). On retrouve alors une homologie avec les propriétés sociales qui lui sont associées: d'un côté, des goûts d'abord populaires, plutôt émergents - faudrait-il dire "ceux du moment »? - et peu différenciés en termes de qualifications sexuées et, de l'autre côté, 
une classe d'abord populaire avant d'être plutôt jeune (plus que le cluster 1, moins que le cluster 3) et plus indifférenciée selon le sexe même si un peu plus féminine (ce qui explique la place significative des romans Harlequin, et le rejet du western ou du film Star Wars).

21 Au-delà des variations du goût populaire liées à l'âge et au sexe, et si l'on s'autorise à alimenter l'analyse par des hypothèses extérieures au jeu de données, on retrouve donc, entre ces trois clusters, différents degrés d'éloignement des pratiques culturelles, expliquant leurs positions relatives sur l'échelle de légitimité en $U$ : des positions à la fois très proches et un peu hiérarchisées, avec « en haut » de l'échelle (au nord-ouest du graphique), la classe 3, plus masculine et juvénile, avec certains goûts enrôlés dans les stratégies d'importation distinctive de produits populaires au sein des mondes légitimes (par exemple des films de science-fiction comme Matrix ou certains segments des variétés, du rap et des musiques électroniques), puis la classe 2 moins différenciée et, « en bas » de l'univers populaire, la classe 1 plus féminine et âgée, avec ses romans Harlequin ou le film Titanic qui apparaissent comme les produits les plus disqualifiants du point de vue de la culture légitime. On trouverait donc ici trois formes d'illégitimité culturelle, c'est-à-dire trois manières de disqualifier depuis le point de vue légitime : la facilité naïve et l'invisibilité des pratiques ringardes et sentimentales (cluster 1) combien de diplômés du supérieur savent le succès continué des Éditions Harlequin ? -, la vulgarité repoussante des produits commerciaux grand public (cluster 2) qu'il s'agit de rejeter ou bien de consommer en passant, et la tyrannie des modes successives imposées par l'industrie culturelle (cluster 3) parmi lesquelles un goût aiguisé saura prélever quelques pépites, voire contribuer à la reconnaissance comme contre-cultures juvéniles et masculines. On voit que l'enquête Pratiques culturelles des Français de 2008 permet de caractériser les goûts populaires à la fois par leur éloignement de la culture légitime et par certains de leurs ressorts « positifs »- l'accessibilité pratique (en termes financiers, en termes de pénétration dans l'environnement quotidien et en termes d'emploi du temps) de la télévision et de la radio et l'accessibilité esthétique des produits les plus diffusés, c'est-à-dire les plus partagés et appréciés en commun. Cette caractérisation " positive » est certes minimale, et nombre de pratiques esthétiques lui échappent: broderie, tuning, tatouage, habillement et maquillage, décoration domestique, etc. ${ }^{26}$ Néanmoins, les données disponibles permettent à la fois d'établir le pouvoir prescriptif de la culture dominante - sa légitimité d'un bout à l'autre de l'espace social - et de suggérer comment ce pouvoir compose avec d'autres habitudes populaires ${ }^{27}$.

22 Le cluster 4 (Annexe 1, tableau 4) est caractérisé par la forte fréquentation de la musique et du cinéma, et la fréquentation moyenne de la télévision et de la lecture. Tout indique ici des goûts intermédiaires touchant à la fois à la culture légitime et à la culture populaire, avec une orientation plus marquée vers la culture légitime à travers, en particulier, le rejet de quelques goûts les plus populaires (des films de science-fiction et d'action) mais aussi des films d'auteur, et des comédies qui sont tantôt vues, tantôt rejetées ; des goûts télévisuels centrés sur les programmes phares de Canal $+{ }^{28}$ (Guignols de l'info ${ }^{29}$, les séries Prison Break et Desperate Housewives) mais aussi quelques émissions « snobs » (Arrêt sur images ${ }^{30}$, Strip-tease ${ }^{31}$ ); des goûts musicaux partagés entre le rock, en premier lieu, mais aussi le hard rock ou le jazz, avec le rejet du "vulgaire » André $\mathrm{Rieu}^{32}$; enfin des lectures centrées sur la bande dessinée, y compris le «snob » Hugo Pratt $^{33}$, et le roman policier, avec des incursions à la fois du côté des livres pratiques ou d'actualité et des romans classiques ou historiques - et le goût «scolaire" pour 
Molière. À cette description il faut néanmoins ajouter des qualifications assez marquées en termes de goûts masculins (rejet des films d'amour et des comédies musicales, goût pour le hard rock, émission Stade 2...) et émergents (rock et musique électronique, BD, Canal+...). En termes de propriétés sociales, on a ainsi affaire à un pôle marqué par des niveaux élevés de capitaux économiques et culturels et par une surreprésentation des hommes et des jeunes adultes: l'interaction entre ces trois propriétés, la première portant vers la culture légitime, les deux autres vers la culture émergente et masculine, explique probablement le caractère "intermédiaire" de cet univers de goût qui concentre les jeunes hommes adultes (très) diplômés. Autrement dit, il s'agit moins d'un univers "de classe moyenne", même si les professions intermédiaires y sont surreprésentées, que d'un univers dont la cohérence "moyenne» repose sur la juxtaposition de profils qui n'ont en commun que de n'être ni les plus «hauts » ni les plus «bas» et de mêler des goûts légitimes, des goûts en voie de légitimation et quelques goûts vulgaires.

Le cluster 6 (Annexe 1, tableau 6) se caractérise par l'intensité des pratiques en matière de cinéma, de musique et de lecture et par la faible fréquentation de la télévision. Il est associé à toutes les modalités de la culture légitime, y compris à travers le rejet des goûts populaires (comédies grand public et Titanic, variétés internationales, musiques électroniques et rap, désintérêt pour la télévision dans son ensemble à l'exception de ses programmes cultivés). On trouve aussi quelques incursions vers des goûts intermédiaires tels que les romans policiers ou la bande dessinée, Star Wars ou le rock et les musiques du monde. En termes de propriétés sociales, ce pôle associe un fort volume de capitaux économiques et culturels et un âge adulte ou avancé, avec une faible différenciation selon le sexe. Le cluster 5 (Annexe 1, tableau 5) se caractérise par le goût pour la lecture et la musique, moins prononcé pour le cinéma, et la faible fréquentation de la télévision. Les goûts qui y sont surreprésentés appartiennent à la culture dominante, dans une variante plus classique ou établie que ceux du cluster 6 : peu de films appréciés, absence du rock, présence de la musique classique (seule modalité très significative), de l'opéra et du jazz, pas d'incursion vers la bande dessinée ou le roman policier. Les propriétés sociales associées manifestent ainsi une variation homologue: de forts capitaux culturels et économiques mais des diplômes un peu moins élevés en moyenne $e^{34}$, un âge plus avancé (concentration des plus de 50 ans) et une plus grande proportion de femmes.

On trouve donc ici une variante établie (ou "classique») de la culture légitime dont la version " émergente» (ou « en voie de canonisation») est représentée par la classe 6. La frontière de la légitimité passe bien «en-dessous » de ces deux classes sur l'échelle en $\mathrm{U}$, et non «entre» elles comme la première interprétation, fondée sur l'identification de l'échelle de légitimité avec l'axe 1, le laissait penser. De plus, l'interprétation de la CAH confirme l'intérêt de saisir d'un même tenant les variables de position les plus corrélées aux premiers axes de l'AFM. Diplôme, âge et sexe "fonctionnent ensemble" pour définir socialement la légitimité culturelle : chaque échelon correspond à une configuration différente de l'homologie entre goûts et espace social, avec la prépondérance relative de telles ou telles modalités de position et de telles ou telles modalités de goût. L'analyse gagne ainsi à ne pas hiérarchiser le poids causal de ces variables, voire à ne pas jouer l'une contre les autres - la classe sociale demeurant dans certains travaux une dernière instance déterminante alors que, dans 
d'autres, le sexe ou (plus souvent) l'âge "prend le pas " sur la classe sociale. Si le diplôme est bien la variable la plus discriminante, et si l'on peut y voir un indice de poids causal, cet indice demeure grossier - d'autant plus que, on l'a vu, s'en tenir à ce seul indicateur conduit à des interprétations imprécises, voire erronées. Ce qui importe, c'est que le diplôme n'agit jamais indépendamment de l'âge et du sexe, et viceversa, pour s'en tenir aux variables prééminentes à l'échelle d'analyse choisie. Il vaut alors la peine d'explorer plus avant leurs interactions afin d'affiner la caractérisation de l'espace social dont résulte l'échelle de légitimité culturelle.

\subsection{Projeter les interactions sur l'AFM : une visualisation des interactions entre diplôme, âge et sexe}

Cette nouvelle piste est la traduction statistique la plus directe de la question posée : la projection, sur l'AFM des goûts, des combinaisons de modalités des variables supplémentaires de position dans les rapports sociaux de classe (indiquée par le diplôme), de sexe et d'âge ${ }^{35}$. Pratiquement, les variables sont combinées deux à deux : d'abord l'âge et le sexe (figure 5), puis le sexe et le diplôme (figure 6) et enfin l'âge et le diplôme (figure 7). Dans chaque figure, on observe les variations de distance entre les modalités analogues pour chaque variable (par exemple, dans la figure 5, entre les femmes âgées de 15 à 24 ans et les hommes eux aussi âgés de 15 à 24 ans).

Fig. 5. Variations concomitantes de l'âge et du sexe sur l'AFM

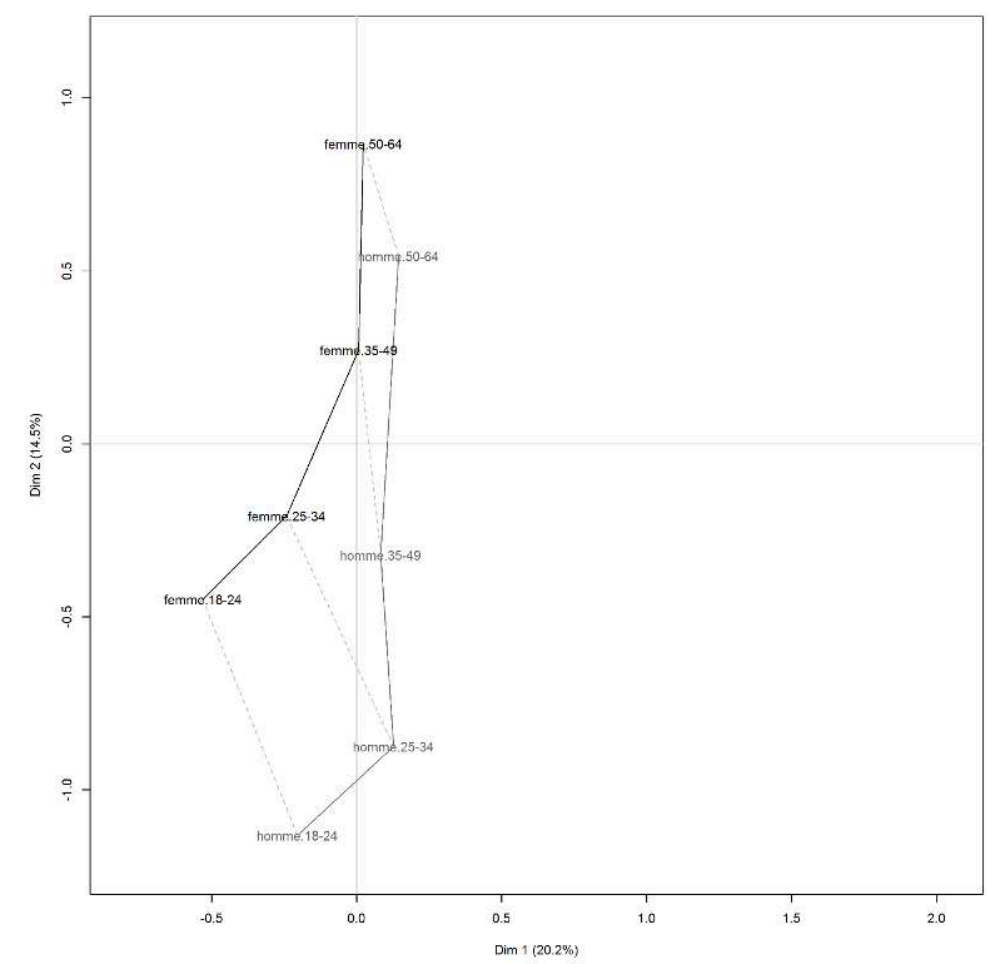

Source : Pratiques culturelles des Français 2008 (DEPS)

Logiquement, à tous les âges (Figure 5), les femmes sont plus souvent du côté des pratiques établies et féminisées, et cet écart avec les hommes est plus accentué chez les jeunes (la différence passe surtout entre les 50-64 ans et les autres) - dans l'autre sens : 
les jeunes sont plus souvent du côté des pratiques émergentes et virilisées, et cet écart est plus accentué chez les hommes. Autrement dit, l'avancée en âge réduit les écarts entre les sexes, et les variations selon l'âge sont plus importantes chez les hommes que chez les femmes : on retrouve le lien entre ancienneté et féminité, et entre juvénilité et masculinité.

Moins attendu, les modalités «homme » s'alignent strictement sur l'axe 2 (Figure 5) alors que les modalités «femme » associées à des classes d'âge jeunes sont (légèrement) sensibles aux variations sur l'axe de la distance à la culture légitime : les femmes jeunes sont à la fois du côté des goûts émergents et masculins, quoique beaucoup moins que leurs homologues masculins, et du côté des goûts populaires les plus répandus, ce qui est moins le cas pour leurs homologues masculins. Sans pouvoir l'établir strictement, il est probable qu'en réalité, cette différence tienne au fait que les femmes s'adonnent moins que les hommes aux pratiques culturelles mesurées. On retrouverait ici la corrélation, sur l'axe 2, entre goûts légitimes et intensité des pratiques. On retrouve aussi l'hypothèse, formulée au sujet du cluster 3 , d'une association entre goûts ringards et sentimentalistes, et disqualification culturelle la plus forte, au point de rendre ces univers populaires féminins et établis quasi-invisibles au point de vue légitime.

Fig. 6. Variations concomitantes du sexe et du diplôme

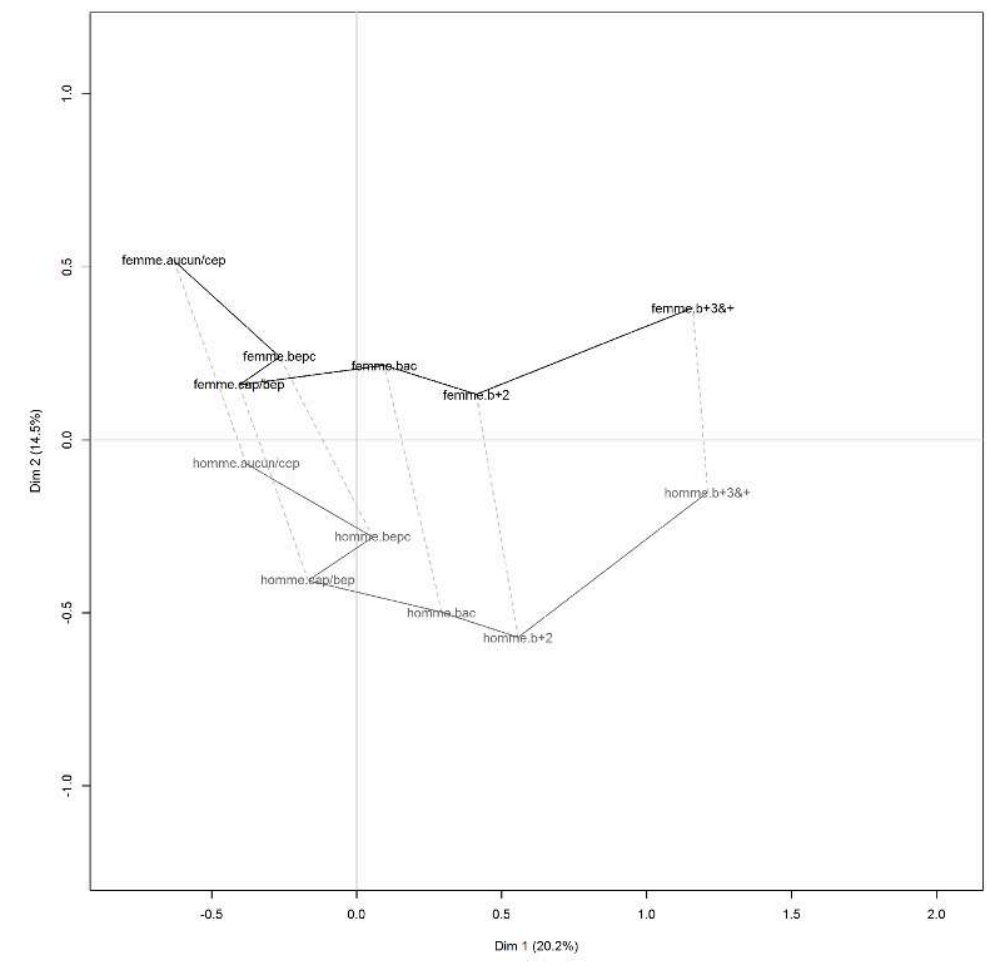

Source : Pratiques culturelles des Français 2008 (DEPS) niveaux de diplôme. À niveau de diplôme donné, hommes et femmes se situent au même niveau sur l'axe 1 ; l'écart entre hommes et femmes reste le même sur l'axe 2, les femmes se situant systématiquement plus haut, i.e. du côté des goûts établis et féminins. 
On voit aussi mieux apparaître l'attraction des niveaux de diplôme élevés et faibles vers le pôle des goûts établis et féminins ${ }^{36}$. On peut alors faire l'hypothèse que, d'un côté, les plus diplômée's se rapprochent de l'univers le plus légitime, qui est associé aux classes dominantes (axe 1) mais aussi établi et féminisé (axe 2), et que, de l'autre côté, les moins diplômés se situent aux côtés des femmes et des individus plus âgés par un effet de structure combinant l'intensité de la pratique (ces trois catégories sont les moins pratiquantes) et l'éloignement maximal des biens établis et féminisés vis-à-vis des normes légitimes.

Fig. 7. Variations concomitantes de l'âge et du diplôme

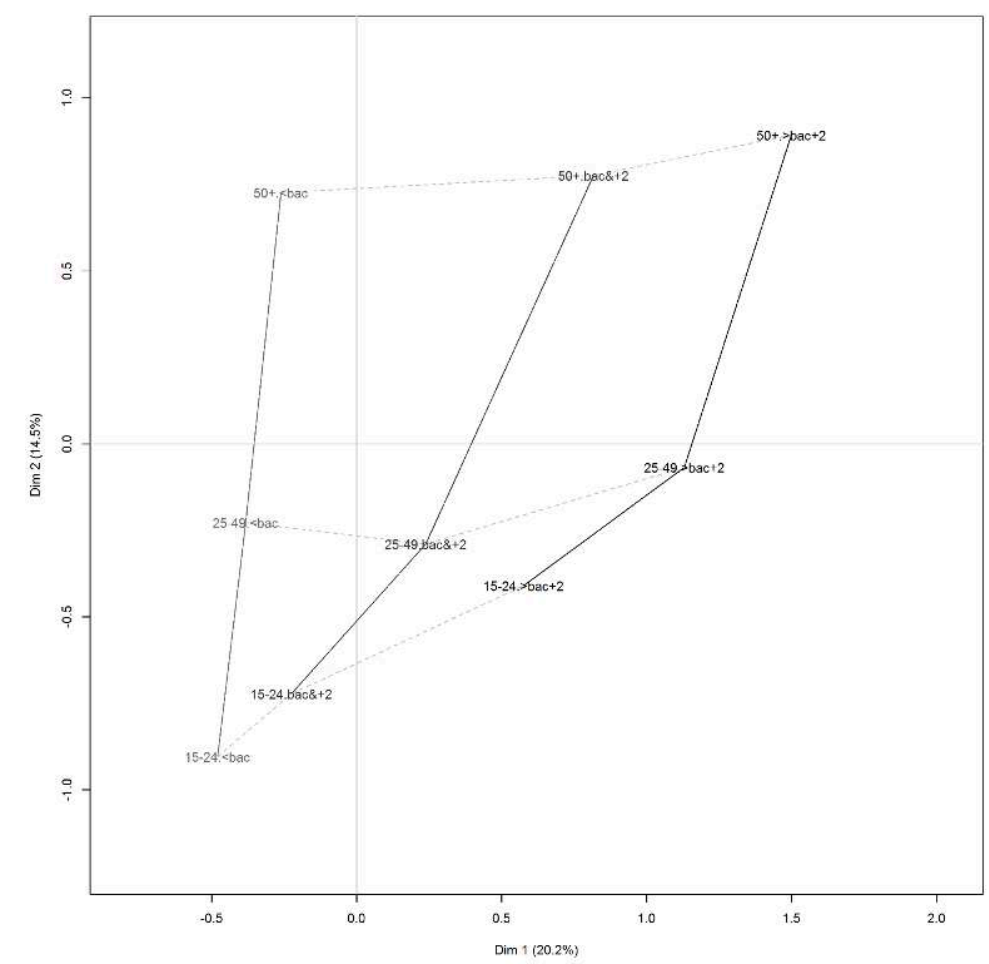

Source : Pratiques culturelles des Français 2008 (DEPS)

31 La figure 7 montre cette fois que les écarts entre niveaux de diplôme sur l'axe de la distance à la culture légitime s'accentuent avec l'âge. La différence passe surtout entre les 15-24 ans et les 25-49 ans, et les 15-24 ans ayant un diplôme supérieur à deux années d'études après le baccalauréat basculent du côté des goûts légitimes. Ceci suggère que cet accroissement des écarts de diplôme avec l'âge est principalement lié au fait qu'un certain nombre des plus jeunes n'ont pas terminé leurs études. Cependant, à nouveau, l'association de la légitimité culturelle avec simultanément l'âge et le diplôme n'est pas invalidée. L'âge modifie peu l'effet de l'absence de diplôme. Mais dès qu'on atteint un niveau minimum de diplôme, les écarts selon l'âge s'accentuent sensiblement - et ce n'est pas lié qu'à la catégorie des 15-24 ans (parfois en cours d'études), cela se vérifie aussi entre les 25-49 ans et les 50 ans et plus.

Par ailleurs, sur l'axe 2, à âge donné, l'augmentation du niveau de diplôme " pousse " vers le côté des goûts établis et féminins, ce constat étant surtout notable pour les 15-24 ans. De plus, toujours sur le deuxième axe, l'âge entraîne plus de variations chez 
les moins diplômés : la position des plus diplômés selon leur âge est donc à la fois plus homogène, plus établie et plus féminine.

Forts des interprétations précédentes, on peut conclure l'exploitation de cet outil de visualisation des interactions entre variables en projetant les trois variables combinées (diplôme, âge et sexe) sur la figure 8. L'écart entre hommes et femmes est plus grand chez les jeunes et chez les peu diplômée's: la différenciation sexuelle des goûts s'estompe avec leur élévation sur l'échelle de légitimité. En même temps, à âge et diplôme égaux, les femmes ont des goûts moins légitimes en bas et au milieu de l'espace social, et plus légitimes en haut: on retrouve ici l'association entre goûts établis et goûts féminins et, plus largement, l'association de l'échelle de légitimité avec l'interaction entre âge, sexe et diplôme. La pointe légitime du U est occupée par les femmes de plus de 50 ans ayant un diplôme supérieur à deux années d'études après le baccalauréat. Parmi les très diplômés, les hommes de $25-49$ ans sont situés, à proximité des 15-24 ans, vers le « creux » émergent et peu légitime du $\mathrm{U}$, alors que les femmes de 25-49 ans sont éloignées des 15-24 ans et nettement plus proches du pôle le plus légitime.

Fig. 8. Projection de la combinaison du diplôme, de l'âge et du sexe sur l'AFM des goûts

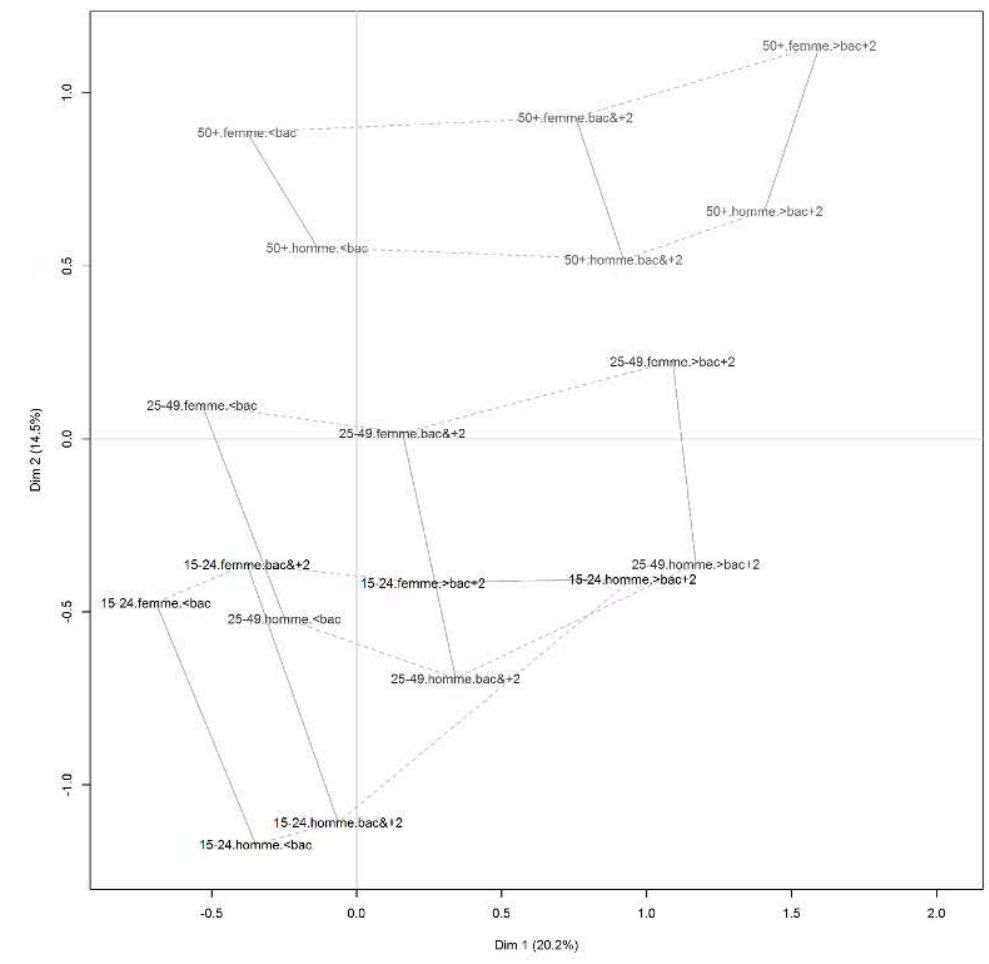

Source : Pratiques culturelles des Français 2008 (DEPS)

\section{Conclusion}

Au moment de l'enquête (2008), la culture légitime n'est pas seulement la culture des classes supérieures: c'est la culture bourgeoise, établie et féminine. Et la culture illégitime n'est pas que la culture populaire: c'est la culture populaire, établie et féminine. Ou faudrait-il dire "la plus illégitime»: elle se distingue, d'un côté, de la 
culture grand public, populaire sans être spécialement associée à des classes de sexe ou d'âge, et, de l'autre côté, de la vulgarité des modes ou contre-cultures populaires, juvéniles et masculines, qui s'avèrent plus proches des univers plus légitimes, peut-être parce qu'elles sont à la fois plus menaçantes car plus revendicatrices de légitimité et plus tentatrices - c'est en tout cas là que les diplômés comme les médias culturels puisent le renouvellement de leurs répertoires de goûts. La légitimité culturelle est ainsi située simultanément dans tous les rapports de pouvoir - de classe, d'âge et de sexe. L'échelle de légitimité est construite par des interactions non linéaires entre ces trois rapports de pouvoir, si bien que, par exemple, la dimension " établie et féminine " est à la fois la plus légitime (musique classique ou poésie) et la plus illégitime (variété française ou romans de la collection Harlequin).

Il y a fort à parier que ces interactions, étudiées ici à partir d'une enquête datée de 2008, puissent varier dans le temps. Il se pourrait par exemple que, alors que l'association entre ancienneté (classicisme, postérité...) et légitimité ne s'est imposée qu'à la fin du XIX ${ }^{e}$ siècle (voir par exemple, pour la peinture : Moulin 1995 ; pour la musique : Weber 1975, Fauquet \& Hennion 2000 ; pour le cinéma, dans les années 1960 : Duval 2016 ou Mary 2011), l'association entre légitimité et féminité soit relativement récente, liée à la tendance générale à une féminisation des pratiques culturelles observées par plusieurs enquêtes depuis les années 1980 (Donnat 2005; Albenga et al. 2014). Ceci permettrait alors de faire retour sur la sexuation de la culture légitime du $\mathrm{XIX}^{\mathrm{e}}$ siècle, entre l'invention " masculine » d'un classicisme sérieux et savant et le goût «féminin» pour l'actualité des loisirs cultivés, associé au lien entre «culture générale ", éducation des jeunes filles et transmission culturelle par les mères (voir par exemple Lenoir 1979 sur le piano; plus généralement Weber 1975). En effet, pour expliquer les interactions observées en 2008, une enquête sociohistorique spécifique serait nécessaire. Étudier les transformations de la légitimité culturelle à partir de la multidimensionnalité des rapports sociaux qui la fondent, c'est-à-dire en systématisant l'analyse en termes d'interactions plutôt qu'en sélectionnant la dimension classiste, âgiste ou sexiste de la légitimité, promet selon nous d'enrichir et d'affiner aussi la connaissance de l'histoire culturelle.

De plus, avec l'association statistique entre légitimité culturelle et goûts dominants parmi les femmes bourgeoises âgées, on retrouve, dans la logique même de La Distinction qui associe propriétés sociales des consommateurs et image publique des consommations, l'image de la culture légitime du point de vue de celleux qui la rejettent : des machins snobs, ringards et destinés aux filles (ou, éventuellement, aux gays quand l'insulte repose sur l'usage de la sexualité pour dire le genre - Détrez 2011; Octobre 2011) ou, inversement, pour celles et ceux qui y adhèrent, des œuvres nobles, sélectionnées par la postérité et élégantes. Le choix des qualificatifs est d'ailleurs malaisé tant la plupart servent de langage à la fois aux rapports de classe, d'âge et de sexe (et d'autres rapports sociaux de pouvoir) : c'est un indice supplémentaire que la légitimité culturelle, comme l'autorité sociale, repose sur l'articulation, variable, de tous les rapports sociaux de pouvoir. Les uns servent de langage aux autres sans qu'il y ait d'ultime instance en la matière : leur « ordre » varie selon les contextes. 


\section{BIBLIOGRAPHIE}

ALBENGA Viviane, HATZIPETROU-ANDRONIKOU Reguina, MARRY Catherine, ROHARIK Ionela (2014).

«Pratiques musicales des amateurs à l'âge adulte : emprise ou déprise du genre? ». In Octobre Sylvie (dir.). Questions de genre, questions de culture. Paris, ministère de la Culture - DEPS : 101-124. AVRIL Christelle (2014). Les Aides à domicile. Un autre monde populaire. Paris, La Dispute, coll. « Corps santé société ».

BARGEL Lucie (2009). Jeunes socialistes/ jeunes UMP. Lieux et processus de socialisation politique. Paris, Dalloz.

BAUdelot Christian, CARTIER Marie, DETREZ Christine (1999). Et pourtant ils lisent... Paris, Seuil.

BENNETT Tony, SAVAGE Mike, silva Elizabeth, WARDE Alan, GAYo-CAL Modesto, WRIGHT David (2009). Culture, Class, Distinction. Londres, Routledge.

BORGES PEREIRA Jose Virgilio (2005). Classes e Culturas de Classe das Famílias Portuenses. Classes sociais e "modalidades de estilização da vida " na cidade do Porto. Porto, Afrontamento/Instituto de Sociologia da Faculdade de Letras da Universidade do Porto.

BOURDIEU Pierre (1979). La Distinction. Critique sociale du jugement. Paris, Minuit.

BOURDIEU Pierre \& PASSERON Jean-Claude (1964). Les Héritiers. Les Étudiants et la culture. Paris, Minuit. CHRISTIN Angèle (2012). « Gender and Highbrow Cultural Participation in the United States ». Poetics, 40(5) : 423-443.

COULANGEON Philippe (2003). « La Stratification sociale des goûts musicaux ». Revue française de sociologie, 44(1) : 3-33.

COULANGEON Philippe (2011). Les Métamorphoses de la distinction. Inégalités culturelles dans la France d'aujourd'hui. Paris, Grasset.

CRENSHAW Kimberlé Williams (2005) [1994]. « Cartographies des marges : intersectionnalité, politique de l'identité et violences contre les femmes de couleur ». Traduit de l'anglais par Oristelle Bonis. Cahiers du Genre, $39: 51-82$.

DETREZ Christine (2011). « Des Shonens pour les garçons, des shojos pour les filles ? Apprendre son genre en lisant des mangas ». Réseaux, 168-169 : 165-186.

DONNAT Olivier (1994). De l'Exclusion à l'éclectisme. Les Français face à la culture. Paris, La Découverte. DONNAT Olivier (2005). « La Féminisation des pratiques culturelles ». In Maruani Margaret (dir.). Femmes, genre et sociétés. L'état des savoirs. Paris, La découverte : 423-431.

DONNAT Olivier (2011). « Pratiques culturelles, 1973-2008. Dynamiques générationnelles et pesanteurs sociales ». Culture études, $7: 1-36$.

DORLIN Elsa (dir.) (2009). Sexe, race et classe. Pour une épistémologie de la domination. Paris, Presses universitaires de France.

DUVAL Julien (2011). « L'Offre et les goûts cinématographiques en France ». Sociologie, 2(1) : 1-18. DUVAL Julien (2016). Le Cinéma au XX $X^{e}$ siècle. Entre loi du marché et règles de l'art. Paris, CNRS éditions. ESCOFIER Brigitte \& PAGÈS Jérôme (2008). Analyses factorielles simples et multiples : objectifs, méthodes et interprétation. Paris, Dunod. 
FABIANI Jean-Louis (2007). Après la culture légitime : objets, publics, autorités. Paris, L'Harmattan. FAUQUET Joël-Marie \& HENNION Antoine (2000). La Grandeur de Bach : l'amour de la musique en France au XIXe siècle. Paris, Fayard.

GLÉVAREC Hervé \& PINET Michel (2009). «La "Tablature” des goûts musicaux : un modèle de structuration des préférences et des jugements ». Revue française de sociologie, 50(3) : 599-640.

GRIGNON Claude \& PASSERON Jean-Claude (1989). Le Savant et le populaire. Misérabilisme et populisme en sociologie et en littérature. Paris, Gallimard/Seuil/EHESS.

JAUNAIT Alexandre \& CHAUVIN Sébastien (2012). « Représenter l'intersection. Les théories de l'intersectionnalité à l'épreuve des sciences sociales ». Revue française de science politique, 62(1) : 5-20.

KHAN Shamus Rahman (2011). Privilege : The Making of an Adolescent Elite at St. Paul's School. Princeton, Princeton University Press.

LAHIRE Bernard (1993). La Raison des plus faibles. Rapport au travail, écritures domestiques et lectures en milieux populaires. Lille, Presses universitaires de Lille.

LAHIRE Bernard (2004). La Culture des individus. Dissonances culturelles et distinction de soi. Paris, La Découverte.

LENOIR Rémi (1979). « Note pour une histoire sociale du piano ». Actes de la recherche en sciences sociales, $28: 79-82$.

LE RENARD Amélie (2019). Le Privilège occidental. Travail, intimité et hiérarchies postcoloniales à Dubaï. Paris, Presses de Sciences Po.

LE ROUX Brigitte \& ROUANET Henry (2004). Geometric Data Analysis: From Correspondence Analysis to Structured Data Analysis. Dordrecht, Kluwer Academic Publishers.

MAIGRET Éric \& MACÉ Éric (2005). Penser les médiacultures. Paris, Armand Colin/INA.

MARY Philippe (2006). La Nouvelle vague et le cinéma d'auteur : socio-analyse d'une révolution artistique. Paris, Seuil.

MAUGER Gérard, POLIAK Claude, PUDAL Bernard (2010). Histoires de lecteurs. Paris, Éditions du Croquant.

MOULIN Raymonde (1995). De la Valeur de l'art. Paris, Flammarion.

остовRE Sylvie (2011). « Du féminin au masculin. Genre et trajectoires culturelles ». Réseaux, 180 : 102-124.

PASQUIER Dominique (2005). Cultures lycéennes. La tyrannie de la majorité. Paris, Éditions Autrement. PEDLER Emmanuel \& ETHIS Emmanuel (2001). « Le Choix des œuvres. Chassé-croisé des publics et des programmations au Festival d'Avignon ». In FABIANI Jean-Louis (dir.). Le Goût de l'enquête. Pour Jean-Claude Passeron. Paris, L'Harmattan : 183-198.

PETERSON Richard A. \& KERN Roger M. (1996). « Changing Highbrow Taste: From Snob to Omnivore ». American Journal of Sociology, 61(5) : 900-907.

PETERSON Richard A. \& SIMKUS Alfred (1992). « How Musical Tastes Mark Occupational Status Groups ». In LAMONT Michèle \& FOURNIER Marcel (dir.). Cultivating differences : Symbolic boundaries and the making of inequality. Chicago, University of Chicago Press : 152-181. 
Prieur Annick, Rosenlund Lennart, Skjott-Larsen Jakob (2008). « Cultural capital today : a case study from Denmark ». Poetics, 36(1) : 45-71.

ROBETTE Nicolas \& ROUEFF Olivier (2014). « An eclectic eclecticism: Methodological and theoretical issues about the quantification of cultural omnivorism ». Poetics, $47: 23-40$.

ROBETTE Nicolas \& ROUEFF Olivier (2017). « L'Espace contemporain des goûts culturels. Homologies structurales entre domaines de pratiques et entre classes sociales ». Sociologie, 8(4) :369-394.

ROOSE Henk, VAN EIJCK Koen, LIEVENS John (2012). «Culture of distinction or culture of openness? Using a social space approach to analyze the social structuring of lifestyles ». Poetics, 40(6) : 491-513.

ROSENLUND Lennart (2000). «Cultural change in Norway: cultural and economic dimensions ». International Journal of Contemporary Sociology, 37(2) : 245-275.

SAVAGE Mike \& GAYO-CAL Modesto (2011). « Unravelling the omnivore: a field analysis of contemporary musical taste in the United Kingdom ». Poetics, 39(5) : 337-335.

SERRE Delphine (2012). « Le Capital culturel dans tous ses états ». Actes de la recherche en sciences sociales, 191-192(1) : 4-13.

SIBLOT Yasmine, CARTIER Marie, COUTANT Isabelle, MASCLET Olivier, RENAHY Nicolas (2015). Sociologie des classes populaires. Paris, Armand Colin.

SKEGGS Beverley (1997). Formations of Class and Gender : Becoming Respectable. Londres, Sage.

WEBER Max (1971). Économie et Société I. Traduction par un collectif dirigé par Jacques Chavy et Éric de Dampierre. Paris, Plon.

WEBER William (1975). Music and the Middle Class. The Social Structure of Concert Life in London, Paris, And Vienna (1815-1848). Londres et Canberra/New York, Croom Helms / Holmes \& Meyer.

\section{ANNEXES}

\section{Annexe 1. Description des six classes de la typologie des goûts culturels}

Les tableaux indiquent : en gras, les modalités dont le résidu est supérieur à 10, en maigre, les modalités dont le résidu est compris entre 5 et 10 , en italique, les modalités dont le résidu est compris entre 1,96 et 5 . Les modalités sont barrées lorsque c'est leur l'absence qui est surreprésentée. 
Tableau 1. Modalités significativement associées au cluster 1

\begin{tabular}{|c|c|}
\hline Cinéma & 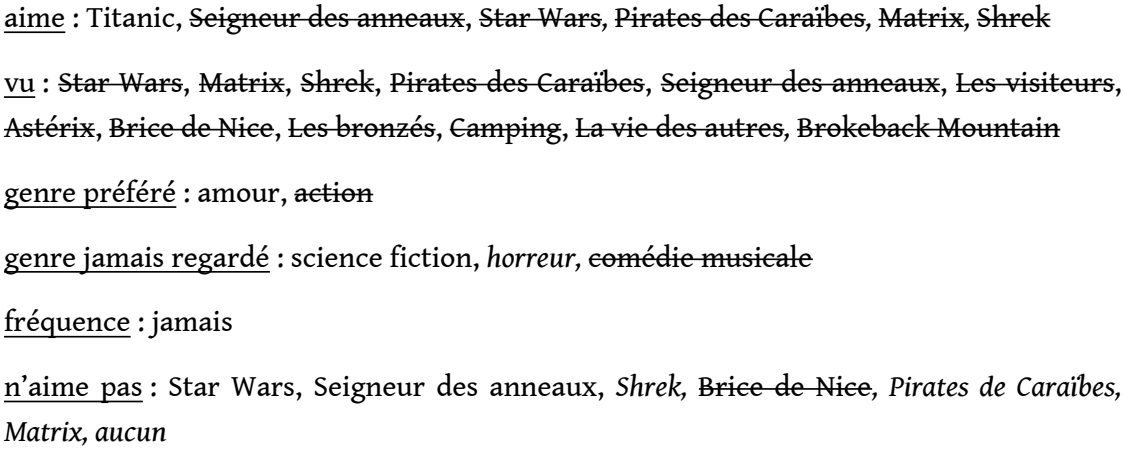 \\
\hline Musique & $\begin{array}{l}\text { écoute souvent : rock, variété intern., jazz, électro, classique, rap, variété française, hard } \\
\text { jamais écouté : rock, rap } \\
\text { genre préféré : variété fr., world } \\
\text { écoute quotidienne }: \text { non } \\
\underline{\text { spectacle }: \text { rock, jazz, classique, opéra, variété }} \\
\underline{\text { ne connaît pas }: \text { Rieu, Boulez }} \\
\underline{\text { aime }: \text { Rieu }}\end{array}$ \\
\hline Télévision & $\begin{array}{l}\text { émission: Les guignols de l'info, Qui veut gagner des millions, Les chiffres et les lettres, } \\
\text { Eapital, Le plus beau cabaret du monde, TV shopping, Arrêt sur images, ta méthode Cautet, } \\
\text { Mercredis de l'histoire, Strip tease, Thalassa, Stade 2, Koh Lanta } \\
\text { série : Les feux de l'amour, Plus belle la vie, Dallas } \\
\text { chaîne }: T F 1 \text {, France } 3 \\
\underline{\text { durée TV }:>30 h, ~ 20-30 h} \\
\text { manque TV : beaucoup } \\
\text { fréquence Arte : jamais }\end{array}$ \\
\hline Livre & $\begin{array}{l}\text { auteur : King } \\
\text { genres lus: } \mathrm{BD}, \text { Harlequin, } r \text { eman policier, histoire, scientifique, elassique, art, } \\
\text { dictionnaire, politique, développement, pratique } \\
\text { nombre de livres lus : aucun } \\
\underline{\text { revues : télé, people }} \\
\text { ne connaît pas: Molière, Pratt, Boulez, Char } \\
\underline{\text { n'aime pas : Molière }} \\
\text { lecture de quotidiens : quoti, régional }\end{array}$ \\
\hline
\end{tabular}


Variables simples : 50 ans et + , aucun diplo / CEP, père agriculteur, mère aucun diplôme, femme, employé, ouvrier, père ouvrier, revenus $=1 / 2 / 3$, père étranger

Variables croisées : 50 ans et $+<$ bac, femme 50 ans et $+<$ bac, femme sans diplôme, 50 ans et + , aucun diplôme, femme 50 ans et + , homme 50 ans et $+<$ bac, homme 50 ans et + , femme, femme 25-49 ans <bac, homme sans diplôme, femme 35-49 ans, femme $<$ bac

Source : Pratiques culturelles des Français 2008 (DEPS). Les libellés complets des questions et des modalités de réponses sont disponibles sur https://sociologie.revues.org/3275 (Annexe 1 de [Robette \& Roueff 2017])

Tableau 2. Modalités significativement associées au cluster 2

\begin{tabular}{|c|c|}
\hline Cinéma & $\begin{array}{l}\text { aime : Camping, Les bronzés, Titanic, Star Wars, Les visiteurs, Astérix } \\
\underline{\mathrm{vu}}: \text { Brice de Nice, La vie des autres, Shrek, Pirates des Caraibes, Astérix, Brokeback } \\
\text { genntain, Camping } \\
\text { genre préféré : comique, action } \\
\text { genre jamais regardé : western } \\
\text { fréquence }: 1-2, \text { jamais } \\
\text { n'aime pas : Star Wars }\end{array}$ \\
\hline Musique & $\begin{array}{l}\text { écoute souvent : variété internationale, classique, jazz, rock } \\
\text { jamais écouté : opéra, classique, jazz, rap } \\
\text { genre préféré : variété internationale, variété française } \\
\text { spectacle : elassique, jazz, rock, epéra, variété } \\
\text { musique seulement : jamais } \\
\text { ne connaît pas : Boulez }\end{array}$ \\
\hline Télévision & $\begin{array}{l}\text { émission : Les enfants de la TV, Super Nanny, La méthode Cauet, Koh Lanta, La nouvelle } \\
\text { star, Qui veut gagner des millions, TV shopping, ça se discute, Mercredis de l'histoire, Arrêt } \\
\text { sur images, Thalassa } \\
\text { chaîne : TF1, M6 } \\
\underline{\text { allume TV : quotidiennement }} \\
\text { durée TV : >30h } \\
\text { fréquence TV : quotidiennement } \\
\text { manque TV : beaucoup } \\
\text { fréquence Arte : jamais, rare }\end{array}$ \\
\hline
\end{tabular}




\begin{tabular}{|c|c|}
\hline Livre & $\begin{array}{l}\text { genre préféré : pratique } \\
\text { genres lus : histoire, scientifique, BD, elassique, politique, roman policier, dictionnaire, } \\
\text { art, Harlequin } \\
\text { nombre de livres lus : aucun } \\
\underline{\text { revues : people, aucune, } T V} \\
\underline{\text { ne connaît pas : Pratt, Molière, Char }} \\
\underline{\text { n'aime pas : Molière }} \\
\text { lecture quotidiens : jamais }\end{array}$ \\
\hline Position & $\begin{array}{l}\text { Variables simples : père ouvrier, CAP/BEP, 25-34 ans, ouvrier, revenus=2, mère sans diplôme, } \\
\text { 15-24 ans, employé, pas de résidence secondaire, privé } \\
\text { Variables croisées : } 25-49 \text { ans <bac, femme } 25-49 \text { ans <bac, femme } 25-34 \text { ans, femme } \\
<\text { bac, femme } 15-24 \text { ans, femme 15-24 ans <bac, <bac, homme 25-49 ans <bac, 25-34 ans, 15-24 } \\
\text { ans <bac, 15-24 ans, homme sans diplôme }\end{array}$ \\
\hline
\end{tabular}

Source : Pratiques culturelles des Français 2008 (DEPS). Les libellés complets des questions et des modalités de réponses sont disponibles sur https://sociologie.revues.org/3275 (Annexe 1 de [Robette \& Roueff 2017])

Tableau 3. Modalités significativement associées au cluster 3

\begin{tabular}{|c|c|}
\hline Cinéma & $\begin{array}{l}\text { aime : Pirates des Caraïbes, Matrix, Star Wars, Seigneur des anneaux, Astérix, Shrek, } \\
\text { Les visiteurs, Camping, Les Bronzés } \\
\frac{\text { a vu }: \text { Matrix, Brice de Nice, Star Wars, Pirate des Caraïbes, Shrek, Seigneur des }}{\text { anneaux, Camping, Astérix, Brokeback Mountain, Les visiteurs }} \\
\text { genre préféré : action, science-fiction } \\
\text { genre jamais regardé : comédie musicale, autre, horreur, amour } \\
\text { fréquence : } 5 \text {-11/ an } \\
\text { n'aime pas : aucun, Star Wars }\end{array}$ \\
\hline Musique & 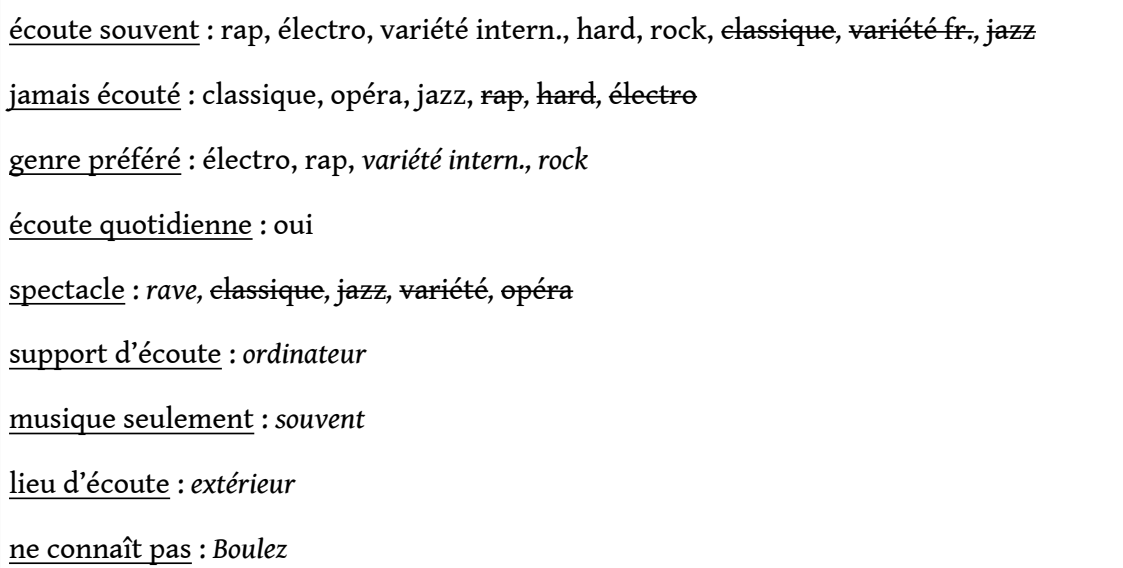 \\
\hline
\end{tabular}




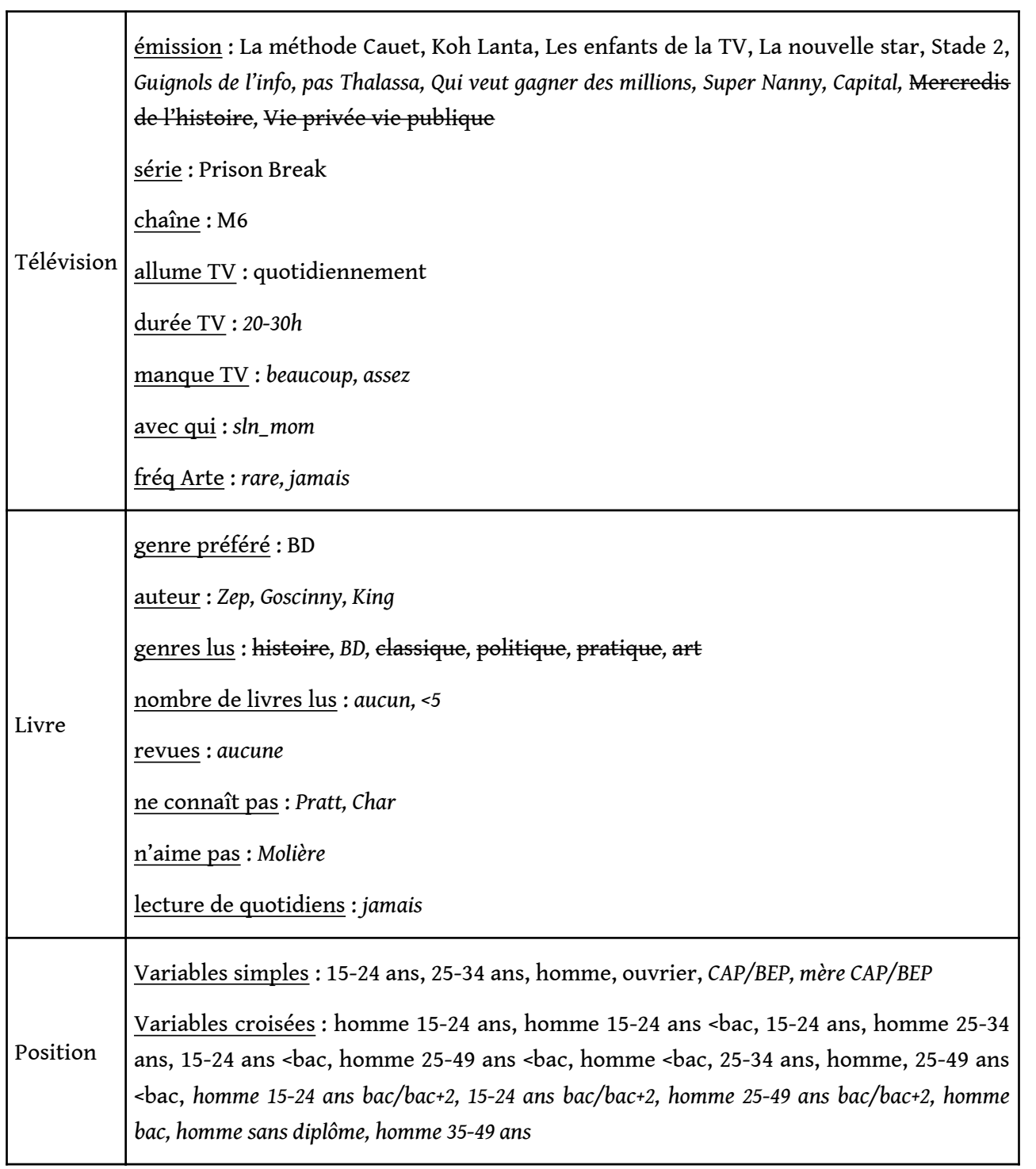

Source: Pratiques culturelles des Français 2008 (DEPS). Les libellés complets des questions et des modalités de réponses sont disponibles sur https://sociologie.revues.org/3275 (Annexe 1 de [Robette \& Roueff 2017]).

Tableau 4. Modalités significativement associées au cluster 4

\begin{tabular}{|c|c|}
\hline Cinéma & $\begin{array}{l}\text { aime : Star Wars, Matrix, Seigneur des anneaux, Shrek, Titanic, Pirates des Caraibes, La } \\
\text { vie des autres, Brokeback Mountain } \\
\text { vu : Matrix, Brokeback Mountain, Star Wars, La vie des autres, Pirates des Caraïbes, } \\
\text { Shrek, Brice de Nice, Seigneur des anneaux, Astérix, Camping, Les visiteurs } \\
\text { genre préféré : science-fiction } \\
\text { genre jamais regardé : comédie musicale, amour, autre, science fiction } \\
\text { fréquence : >12, 5-11, 6-10 } \\
\underline{\text { n'aime pas : Titanic, Star Wars, Camping, Brice de Nice }}\end{array}$ \\
\hline
\end{tabular}




\begin{tabular}{|c|c|}
\hline Musique & $\begin{array}{l}\text { écoute souvent : rock, hard, jazz, électro, variété fr., rap, classique } \\
\text { jamais écouté : classique, opéra, jazz, hard, variété intern., rock } \\
\text { genre préféré : rock } \\
\text { écoute quotidienne : oui } \\
\underline{\text { spectacle }: \text { rock, jazz, rave, classique, opéra, variété }} \\
\underline{\text { support }: \text { ordinateur, } C D} \\
\text { musique seulement : souvent, quotidiennement, rare } \\
\text { lieu d'écoute }: \text { home, extérieur } \\
\underline{\text { n'aime pas }: \text { Rieu }}\end{array}$ \\
\hline Télévision & $\begin{array}{l}\text { émission : Guignols de l'info, Arrêt sur images, Strip tease, Mercredis de l'histoire, Qui } \\
\text { série : Prison Break, Desperate Housewives } \\
\underline{\text { chaîne : Canal+, aucune }} \\
\underline{\text { durée TV }:<10 h, 10-15 \mathrm{~h}} \\
\underline{\text { fréq }: 3-4 \text { par semaine }} \\
\underline{\text { manque TV }: \text { non, peu }} \\
\text { fréquence Arte : chaque semaine, chaque mois, quotidiennement }\end{array}$ \\
\hline Livre & $\begin{array}{l}\text { genre préféré : roman policier, BD, autres romans } \\
\text { auteur : King, Rowling, Goscinny, Nothomb } \\
\text { genres lus : BD, scientifique, roman policier, histoire, dictionnaire, classique, pratique, } \\
\text { politique, art, roman historique, actualité, développement } \\
\text { nombre de livres lus }: 11-20,>20 \\
\underline{\text { connait }: \text { Pratt }} \\
\underline{\text { aime }: \text { Molière }}\end{array}$ \\
\hline Position & $\begin{array}{l}\text { Variables simples: }>=\mathrm{bac}+3 \text {, revenus }=5 \text {, père cadre, bac }+2 \text {, homme, cadre, mère bac }+2 \text {, } \\
\text { profession intermédiaire, } 25-34 \text { ans, résidence secondaire, père profession intermédiaire, mère } \\
\text { bac, mère CAP/BEP, bac, public } \\
\text { Variables croisées : homme } 25-49 \text { ans }>\mathrm{bac}+2 \text {, homme }>\mathrm{bac}+2,25-49 \text { ans }>\mathrm{bac}+2 \text {, homme } \\
25-49 \text { ans bac/bac }+2 \text {, homme } 25-34 \text { ans, }>\mathrm{bac}+2,25-49 \text { ans bac } / \mathrm{bac}+2 \text {, bac }+2 \text {, homme, } \\
\text { homme } 35-49 \text { ans, } 25-34 \text { ans, homme bac, bac, } 15-24 \text { ans }>\text { bac }+2 \text {, femme } 25-49 \text { ans bac/bac }+2 \text {, } \\
\text { femme } 25-49 \text { ans }>b a c+2 \text {, homme } 15-24 \text { ans }>b a c+2\end{array}$ \\
\hline
\end{tabular}

Source : Pratiques culturelles des Français 2008 (DEPS). Les libellés complets des questions et des modalités de réponses sont disponibles sur https://sociologie.revues.org/3275 (Annexe 1 de [Robette \& Roueff 2017]). 
Tableau 5. Modalités significativement associées au cluster 5

\begin{tabular}{|c|c|}
\hline Cinéma & $\begin{array}{l}\text { aime : aucun, Les bronzés, Seigneur des anneaux, Pirates des Caraïbes, Star Wars, } \\
\text { Matrix, } \\
\text { vu : Brice de Nice, Pirates des Carä̈bes, Matrix, Shrek, Astérix, Seigneur des anneaux, } \\
\text { Titanic, Camping, Les bronzés, Star Wars, } \\
\text { genre préféré : historique, documentaire, autre, comédie dramatique, comique } \\
\text { genre jamais regardé : horreur, action, science fiction } \\
\text { fréquence : } 5-11 \\
\underline{\text { n'aime pas : Matrix, Les bronzés, Les visiteurs, Shrek }}\end{array}$ \\
\hline Musique & $\begin{array}{l}\text { écoute souvent : classique, jazz, variété internationale, world, opéra, électro, rap } \\
\text { jamais écouté : opéra, rap, électro, elassique, hard, jazz, } \\
\text { genre préféré : classique, jazz, world } \\
\text { spectacle : classique, opéra, jazz, variété } \\
\underline{\text { support : radio }} \\
\underline{\text { aime }: \text { Boulez, Rieu }} \\
\underline{\text { 'aime pas }: \text { Boulez }}\end{array}$ \\
\hline Télévision & 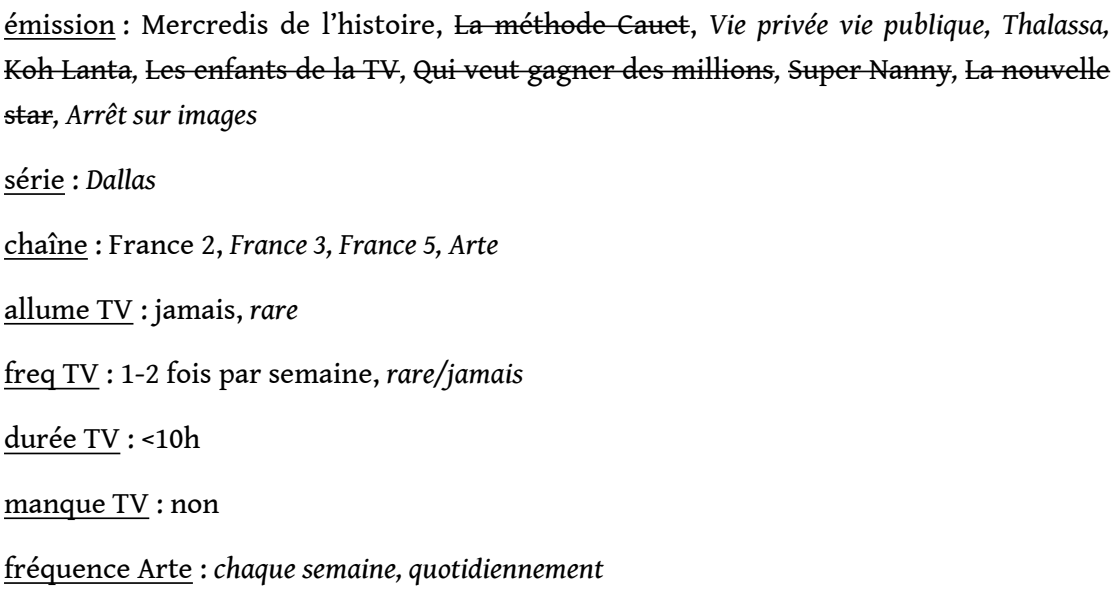 \\
\hline Livre & $\begin{array}{l}\text { genre préféré : histoire, autre roman } \\
\text { auteur : d'Ormesson } \\
\text { genres lus : art, histoire, développement, contemporain, politique, classique, } \\
\text { dictionnaire, romans historiques, actualité, poésie, scientifique, biographies, pratique } \\
\text { nombre de livres lus : >20, 6-10, 11-20 } \\
\text { revues : actualité, mode, aucune, } \\
\text { connaît : Char } \\
\text { aime : Molière }\end{array}$ \\
\hline
\end{tabular}




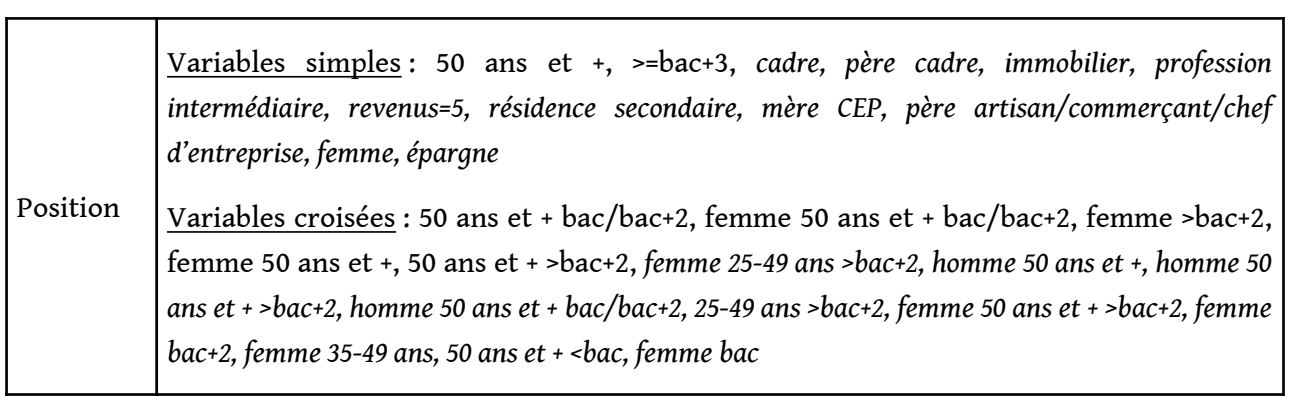

Source : Pratiques culturelles des Français 2008 (DEPS). Les libellés complets des questions et des modalités de réponses sont disponibles sur https://sociologie.revues.org/3275 (Annexe 1 de [Robette \& Roueff 2017])

Tableau 6. Modalités significativement associées au cluster 6

\begin{tabular}{|c|c|}
\hline Cinéma & $\begin{array}{l}\text { aime : La vie des autres, Brokeback Mountain, Fitanie, tes bronzés, aucun, Eamping, Les } \\
\text { visiteurs } \\
\text { vu }: \text { La vie des autres, Brokeback Mountain, Eamping, Titanie, Star Wars, Brice de Nice, } \\
\text { Les bronzés, Astérix } \\
\text { genre préféré : autre, comédie dramatique, historique, action, comique, documentaire } \\
\text { genre jamais regardé : horreur } \\
\text { fréquence }:>12 \\
\text { n'aime pas }: \text { Camping, Les bronzés, Brice de Nice, Les visiteurs, Pirates des Caraibes, } \\
\text { Titanic, Star Wars }\end{array}$ \\
\hline Musique & 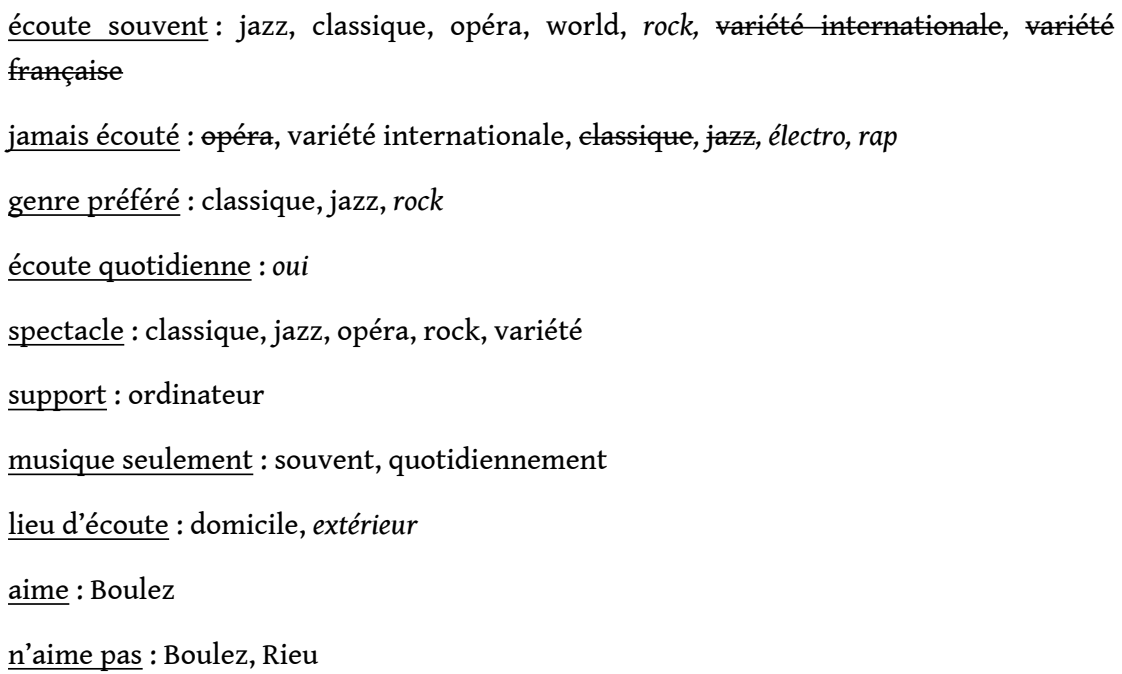 \\
\hline
\end{tabular}




\begin{tabular}{|c|c|}
\hline Télévision & 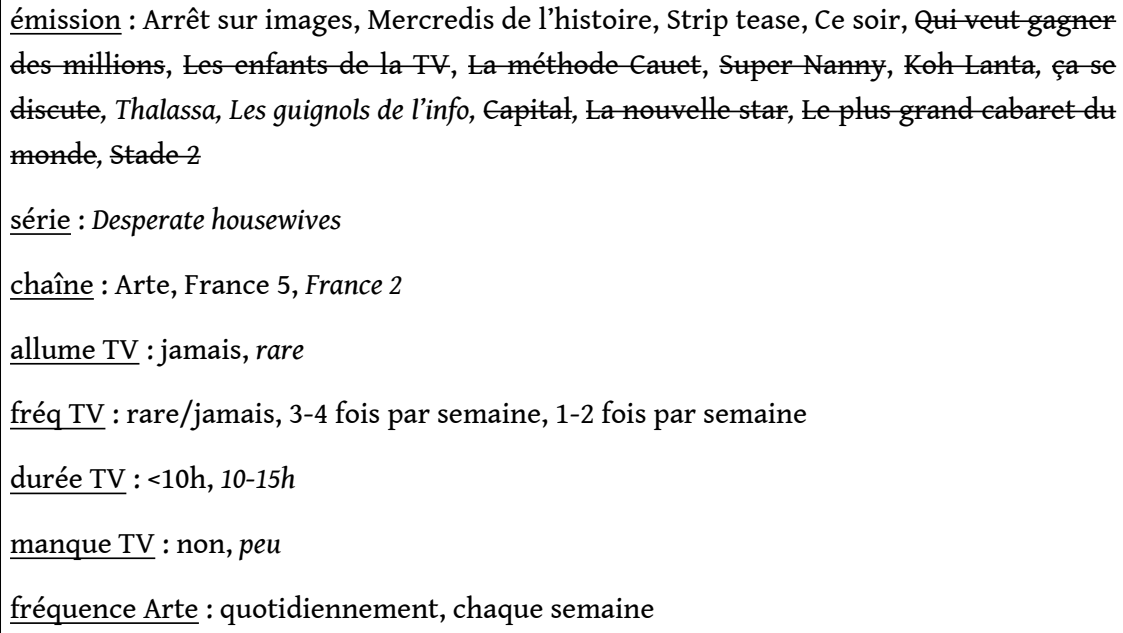 \\
\hline Livre & 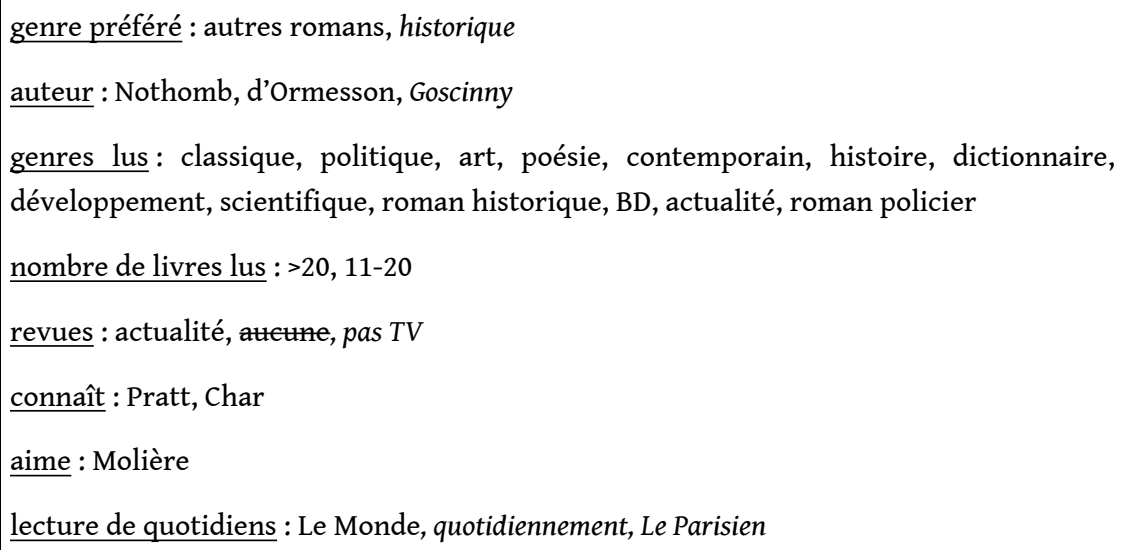 \\
\hline Position & 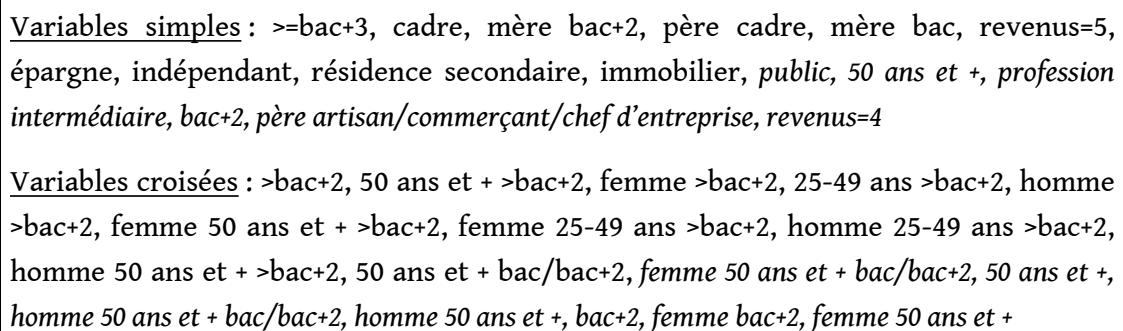 \\
\hline
\end{tabular}

\section{Annexe 2. Une mesure des effets d'interaction à l'aide de régressions linéaires}

Afin de corroborer le rôle des interactions entre diplôme, sexe et âge dans la structuration des goûts culturels, nous adoptons dans cette annexe une autre approche, tirant profit de modèles de régressions linéaires. Les coordonnées des individus sur le premier puis sur le deuxième axe de l'AFM sont utilisées comme variable dépendante pour une série de régressions linéaires emboîtées, introduisant pas à pas en tant que variables indépendantes le diplôme, le sexe et l'âge, puis leurs interactions d'ordre 1 et 
2. Cette approche est à strictement parler redondante avec celles adoptées dans le corps de l'article : ce ne sont que des manières différentes de rendre visible la structuration des données étudiées en termes d'interactions entre variables à partir d'outils de mesure de la variance. Elle vise donc surtout à offrir un élément de conviction supplémentaire aux adeptes de la quantification des effets d'interaction par la modélisation de régressions linéaires.

Comme dans les analyses précédentes, pour des questions d'effectifs, les tranches d'âge ont été groupées en trois catégories (moins de 25 ans; 25 à 49 ans ; 50 ans et plus), de même que le niveau de diplôme (inférieur au bac ; bac à bac+2; supérieur à bac +2 ).

Les modèles $1 \mathrm{~A}, 1 \mathrm{~B}$ et $1 \mathrm{C}$ estiment les effets bruts du diplôme, du sexe et de l'âge sur la position sur l'axe 1 de l'AFM (Tableau 7). Ces effets bruts correspondent à ce que l'on observe lorsqu'on projette ces variables en supplémentaires sur le graphique de l'AFM. On retrouve donc des résultats déjà connus : le niveau de diplôme a un effet positif sur la position sur l'axe 1 (effet très prononcé pour les diplômes les plus élevés) ; le fait d'être une femme a un effet négatif mais assez faible ; l'âge a un effet positif.

Le modèle 1D estime les effets partiels des trois variables indépendantes (diplôme, âge, sexe). Ces effets partiels sont proches des effets bruts observés dans les modèles précédents. Il y a donc peu d'effets de structure dans la relation entre les trois variables et la variable dépendante (coordonnées des individus sur l'axe 1). À la marge, on constate toutefois une légère augmentation des effets de diplôme, une diminution des effets d'âge et une augmentation de l'effet du sexe.

Le modèle $1 \mathrm{E}$ introduit les effets d'interaction ${ }^{37}$ d'ordre 1 , c'est-à-dire entre les trois variables indépendantes prises deux à deux. Les effets principaux du diplôme et de l'âge restent positifs mais diminuent très nettement : ils semblent pour partie " captés » par les interactions. De fait, les effets d'interaction entre diplôme et âge sont positifs, et d'autant plus forts que le diplôme ou l'âge sont élevés.

En revanche, l'effet principal du fait d'être une femme augmente notablement, passant de $-0,86$ à $-1,75$. Dans le même temps, les interactions montrent qu'être une femme diplômée (plutôt qu'un homme peu diplômé) ou une femme adulte ou âgée (plutôt qu'un homme jeune) a un effet positif, et ce d'autant plus que le diplôme ou l'âge sont élevés. L'effet principal du sexe, « toute chose égale d'ailleurs » (c'est-à-dire ici à âge et diplôme constant), pousse donc les femmes du côté des goûts les moins légitimes, alors que l'interaction avec le diplôme ou l'âge les pousse du côté des goûts légitimes.

Le dernier modèle (1F) est le modèle saturé : il introduit, en plus des interactions d'ordre 1 , les interactions d'ordre 2, c'est-à-dire entre les trois variables indépendantes prises ensemble. Le sens des effets principaux reste inchangé par rapport au modèle précédent et la taille des effets est peu modifiée, excepté celle du plus haut niveau de diplôme, qui augmente nettement. La plupart des effets d'interactions d'ordre 1 diminuent et/ou voient leur $\mathrm{p}$-value augmenter à des niveaux qui incitent à ne pas les interpréter. Il est donc probable que les effets d'interaction d'ordre 2 viennent « capter » une partie des effets d'interaction d'ordre 1 observés dans le modèle $1 \mathrm{E}$. Cependant, on remarquera que l'effet d'un diplôme « bac à bac+2 » combiné à l'âge le plus élevé reste positif et très fort (supérieur à 3) et que la combinaison du même niveau de diplôme avec la tranche d'âge « 25-49 ans " a un effet positif plus modeste (entre 1 et 1,5) mais qui se maintient. Parmi les effets d'interaction d'ordre 2, deux sont particulièrement forts (et positifs) : le fait d'être une femme de diplôme supérieur à 
bac+2 combiné au fait d'avoir plus de 50 ans ou, de manière moins marquée, entre 25 et 49 ans.

En résumé, on constate tout d'abord que le diplôme est bien la propriété la plus structurante pour expliquer la position des individus sur le premier axe de l'AFM : l'effet principal d'un diplôme supérieur à bac+2 est le plus fort de tous les effets observés dans le modèle saturé, et le diplôme est présent dans toutes les interactions de taille supérieure à 1 (en valeur absolue).

De plus, on constate l'existence d'effets d'interaction entre les trois rapports sociaux que nous étudions : le fait d'être une femme très diplômée et âgée d'au moins 25 ans (et a fortiori de plus de 50 ans) oriente de manière très marquée les individus du côté des goûts les plus légitimes.

Tableau 7 - Régressions linéaires de la position sur l'axe 1 de l'AFM en fonction du diplôme, du sexe et de l'âge

\begin{tabular}{|c|c|c|c|c|c|c|c|c|c|c|c|c|}
\hline & \multicolumn{2}{|c|}{ Modèle $1 \mathrm{~A}$} & \multicolumn{2}{|c|}{ Modèle 1B } & \multicolumn{2}{|c|}{ Modèle $1 \mathrm{C}$} & \multicolumn{2}{|c|}{ Modèle 1D } & \multicolumn{2}{|c|}{ Modèle $1 \mathrm{E}$} & \multicolumn{2}{|c|}{ Modèle 1F } \\
\hline & estim. & $\begin{array}{l}\mathrm{p}- \\
\text { value }\end{array}$ & estim. & $\begin{array}{l}\mathrm{p}- \\
\text { value }\end{array}$ & estim. & $\begin{array}{l}\mathrm{p}- \\
\text { value }\end{array}$ & estim. & $\begin{array}{l}\mathrm{p}- \\
\text { value }\end{array}$ & estim. & $\begin{array}{l}\mathrm{p}- \\
\text { value }\end{array}$ & estim. & $\begin{array}{l}\mathrm{p}- \\
\text { value }\end{array}$ \\
\hline (Intercept) & -1.59 & 0 & 0.57 & 0 & -1.58 & 0 & -2.53 & 0 & -1.44 & 0 & -1.57 & 0 \\
\hline Diplôme & & & & & & & & & & & & \\
\hline (réf = <bac) & & & & & & & & & & & & \\
\hline bac\&+2 & 2.64 & 0 & & & & & 2.85 & 0 & 1.05 & 0.0315 & 1.16 & 0.0798 \\
\hline$>\mathrm{bac}+2$ & 6.52 & 0 & & & & & 6.6 & 0 & 3.99 & 0 & 5.66 & 0 \\
\hline Sexe & & & & & & & & & & & & \\
\hline (réf = homme) & & & & & & & & & & & & \\
\hline femme & & & -0.49 & 0.002 & & & -0.86 & 0 & -1.75 & 0 & -1.48 & 0.0052 \\
\hline Âge & & & & & & & & & & & & \\
\hline (réf $=<25$ ans) & & & & & & & & & & & & \\
\hline $25-49$ ans & & & & & 1.91 & 0 & 1.14 & 0 & 0.31 & 0.3744 & 0.44 & 0.2516 \\
\hline 50 ans et + & & & & & 2.63 & 0 & 2.44 & 0 & 0.71 & 0.0666 & 0.86 & 0.0432 \\
\hline Diplôme:Sexe & & & & & & & & & & & & \\
\hline $\begin{array}{l}\text { (réf } \\
<\text { bac:homme) }\end{array}$ & & & & & & & & & & & & \\
\hline bac\&+2:femme & & & & & & & & & 0.32 & 0.2852 & 0.06 & 0.9505 \\
\hline
\end{tabular}




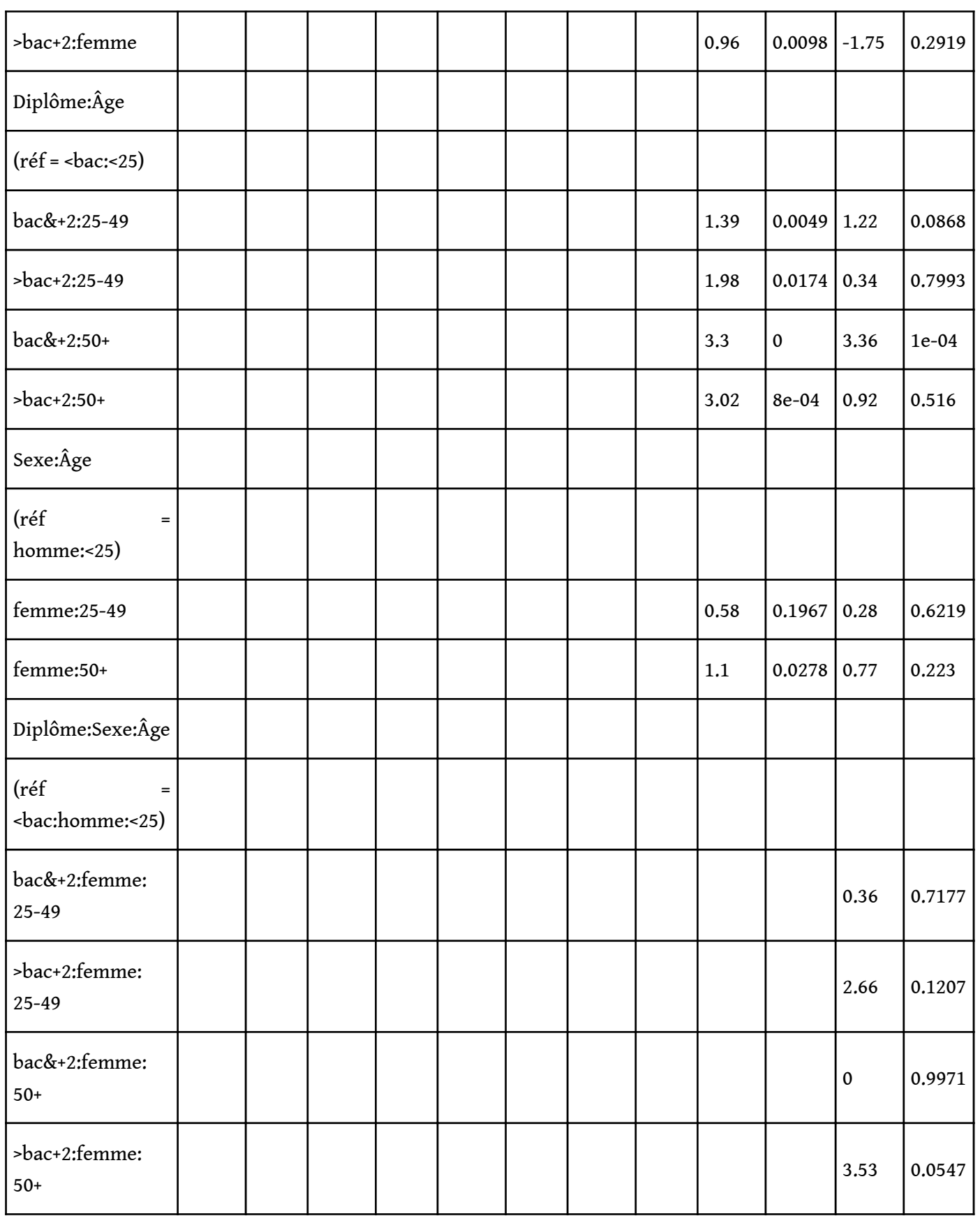

Source : Pratiques culturelles des Français 2008 (DEPS)

Tableau 8 - Régressions linéaires de la position sur l'axe 2 de l'AFM en fonction du diplôme, du sexe et de l'âge

\begin{tabular}{|l|l|l|l|l|l|l|l|l|l|l|l|l|}
\hline & \multicolumn{2}{|l|}{ Modèle 2A } & \multicolumn{2}{l|}{ Modèle 2B } & \multicolumn{2}{l|}{ Modèle 2C } & \multicolumn{2}{l|}{ Modèle 2D } & \multicolumn{2}{l|}{ Modèle 2E } & \multicolumn{2}{l|}{ Modèle 2F } \\
\hline & estim. & $\begin{array}{l}\text { p- } \\
\text { value }\end{array}$ & estim. & $\begin{array}{l}\text { p- } \\
\text { value }\end{array}$ & estim. & $\begin{array}{l}\text { p- } \\
\text { value }\end{array}$ & estim. & $\begin{array}{l}\text { p- } \\
\text { value }\end{array}$ & estim. & $\begin{array}{l}\text { p- } \\
\text { value }\end{array}$ & estim. & $\begin{array}{l}\text { p- } \\
\text { value }\end{array}$ \\
\hline (Intercept) & -0.18 & 0.0458 & -1.3 & 0 & -2.83 & 0 & -3.83 & 0 & -4.19 & 0 & -4.22 & 0 \\
\hline
\end{tabular}




\begin{tabular}{|c|c|c|c|c|c|c|c|c|c|c|c|c|}
\hline \multicolumn{13}{|l|}{ Diplôme } \\
\hline (réf = <bac) & & & & & & & & & & & & \\
\hline $\mathrm{bac} / \mathrm{bac}+2$ & -0.28 & 0.0568 & & & & & -0.22 & 0.0825 & 0.21 & 0.6123 & 0.07 & 0.9051 \\
\hline$>\mathrm{bac}+2$ & 0.62 & $8 e-04$ & & & & & 0.6 & $1 \mathrm{e}-04$ & 1.05 & 0.1381 & 2.36 & 0.0324 \\
\hline Sexe & & & & & & & & & & & & \\
\hline (réf = homme) & & & & & & & & & & & & \\
\hline femme & & & 2.12 & 0 & & & 2.08 & 0 & 2.4 & 0 & 2.47 & 0 \\
\hline Âge & & & & & & & & & & & & \\
\hline (réf $=<25$ ans) & & & & & & & & & & & & \\
\hline $25-49$ & & & & & 2.08 & 0 & 1.92 & 0 & 2.29 & 0 & 2.31 & 0 \\
\hline $50+$ & & & & & 5.52 & 0 & 5.36 & 0 & 6.04 & 0 & 6.1 & 0 \\
\hline Diplôme:Sexe & & & & & & & & & & & & \\
\hline $\begin{array}{l}\text { (réf } \\
<\text { bac:homme) }\end{array}$ & & & & & & & & & & & & \\
\hline $\mathrm{bac} / \mathrm{bac}+2:$ femme & & & & & & & & & 0.23 & 0.3709 & 0.47 & 0.5482 \\
\hline$>$ bac $+2:$ femme & & & & & & & & & -0.01 & 0.9647 & -2.09 & 0.1358 \\
\hline Diplôme:Âge & & & & & & & & & & & & \\
\hline (réf = <bac:<25) & & & & & & & & & & & & \\
\hline $\mathrm{bac} / \mathrm{bac}+2: 25-49$ & & & & & & & & & -0.74 & 0.0782 & -0.58 & 0.3379 \\
\hline$>$ bac $+2: 25-49$ & & & & & & & & & -0.56 & 0.4269 & -1.86 & 0.1009 \\
\hline $\mathrm{bac} / \mathrm{bac}+2: 50+$ & & & & & & & & & -0.22 & 0.6417 & -0.04 & 0.9553 \\
\hline$>\mathrm{bac}+2: 50+$ & & & & & & & & & -0.26 & 0.7331 & -1.82 & 0.1303 \\
\hline Sexe:Âge & & & & & & & & & & & & \\
\hline $\begin{array}{l}\text { (réf } \\
\text { homme: }<25)\end{array}$ & & & & & & & & & & & & \\
\hline femme:25-49 & & & & & & & & & -0.19 & 0.6186 & -0.25 & 0.6095 \\
\hline femme:50+ & & & & & & & & & -1.11 & 0.0087 & -1.24 & 0.02 \\
\hline Diplôme:Sexe:Âge & & & & & & & & & & & & \\
\hline
\end{tabular}




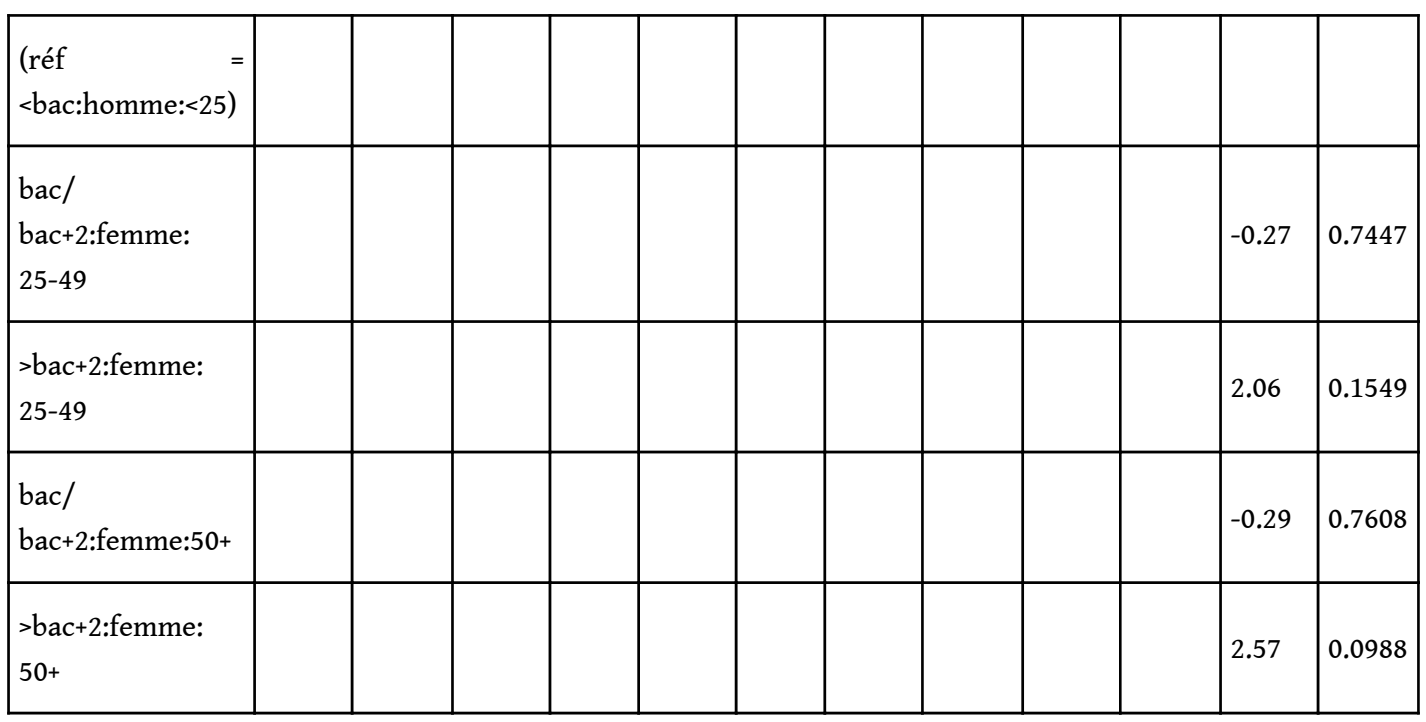

Source : Pratiques culturelles des Français 2008 (DEPS)

La deuxième série de régressions linéaires modélise la position des individus sur l'axe 2 en fonction du diplôme, du sexe et de l'âge (Tableau 8). Les modèles $2 \mathrm{~A}, 2 \mathrm{~B}$ et $2 \mathrm{C}$ reproduisent les résultats de la projection en supplémentaires des trois variables explicatives. L'âge s'échelonne de bas en haut du plan factoriel à mesure qu'il croît et présente le plus fort pouvoir discriminant. Le sexe est également discriminant, le fait d'être une femme étant associé à une position en haut du plan. Le diplôme est nettement moins discriminant, et on retrouve la disposition en « $\mathrm{U}$ » de ses modalités : avoir un diplôme supérieur à bac +2 est associée à une position du côté positif de l'axe 2 , alors que le niveau intermédiaire (bac ou bac +2$)$ est plus bas que le niveau inférieur au bac.

Dans le modèle 2D, les coefficients sont très peu modifiés par rapport aux modèles précédents, indiquant la faiblesse des effets de structure entre diplôme, sexe et âge dans la deuxième dimension du plan.

L'introduction des interactions d'ordre 1 (modèle 2E) modifie relativement peu les effets principaux, dans le sens d'une légère accentuation. Le principal effet d'interaction concerne les femmes de plus de 50 ans : il est négatif, alors même que les effets principaux des modalités « femme » et " plus de 50 ans » sont tous deux positifs. Secondairement, on constate un léger effet négatif de l'interaction entre les modalités intermédiaires de diplôme et d'âge (« bac à bac +2 et « 25-49 ans »).

Le modèle saturé, i.e. avec les interactions d'ordre 1 et 2 (modèle 2F), fait apparaitre quelques changements par rapport au modèle précédent. Tout d'abord, l'effet positif du plus haut niveau de diplôme est très nettement accentué, passant de 1,05 à 2,36. Les autres effets principaux restent à peu près identiques. Par ailleurs, quatre effets d'interaction d'ordre 1 sont maintenant notables, et négatifs : l'interaction entre le fait d'être une femme et d'avoir un haut niveau de diplôme ; entre le fait d'avoir un haut diplôme et d'avoir entre 25 et 49 ans ou plus de 50 ans; entre le fait d'être une femme et d'avoir plus de 50 ans. Comme dans le modèle précédent, ces effets d'interaction notables sont de sens contraire aux effets principaux des modalités concernées.

Enfin, on observe deux effets d'interaction d'ordre 2 positifs et relativement forts : ils caractérisent le fait d'être une femme très diplômée âgée de plus de 50 ans, ou 
secondairement de 25 à 49 ans. Autrement dit, comme pour l'axe 1, l'interaction entre le fait d'être une femme, des diplômes élevés et un âge élevé " pousse » les individus du côté des goûts les plus légitimes, qui se situent dans le quart Nord-Est du plan factoriel.

Ces deux séries de régressions linéaires confirment donc les hypothèses et les résultats présentés dans le corps de l'article. Les trois rapports sociaux analysés contribuent à structurer les goûts en matière de culture. Les trois propriétés (diplôme élevé, femme, âge élevé) s'additionnent (effets principaux) mais aussi se conjuguent (effets d'interaction d'ordre 2) pour définir le goût légitime, qui est à la fois cultivé, féminin et établi.

\section{NOTES}

1. L'étude statistique de la répartition sociale des pratiques culturelles a été menée par exemple en Australie (Bennett et al. 1999), en Norvège (Rosenlund 2000), à Porto (Borges Pereira 2005), à Aalborg au Danemark (Prieur et a.l 2008), en Grande-Bretagne (Bennett et al. 2009).

2. De nombreux travaux se sont focalisés sur les goûts musicaux, en particulier autour de l'hypothèse d'une substitution de l'opposition entre omnivorisme dominant (apprécier plusieurs genres de différents niveaux de légitimité culturelle) et univorisme populaire (apprécier un seul genre illégitime) à l'opposition entre snobisme bourgeois et vulgarité populaire mise en avant dans La Distinction. Pour une bibliographie et une mise au point, sur la base de la reproduction de diverses méthodes de construction statistique de l'échelle de légitimité mises en œuvre par les différents auteurs, voir Robette \& Roueff (2014).

3. Il s'agit de la cinquième vague d'une enquête lancée en 1973 et renouvelée en 1981, 1988, 1997-1998, 2008 et 2018-2019 (données non encore accessibles à la date d'écriture de cet article). L'échantillon de 2008 contient 5008 individus représentatifs de la population française de plus de 15 ans. Pour plus d'informations, voir le site de l'enquête Pratique culturelle des Français .

4. Nous avons montré par ailleurs que la « montée de l'éclectisme » est avant tout un artefact méthodologique et épistémologique. Elle est, en outre, non seulement faible sur le plan empirique, mais aussi entièrement expliquée par l'accroissement global des consommations culturelles omnibus (celles qui concernent la majorité de toutes les classes sociales, comme les variétés en musique) et par la diversification de l'offre depuis les années 1960, soit deux phénomènes qui ne disent rien des manières de consommer (Robette \& Roueff 2014). Tout laisse à penser qu'avec le creusement des inégalités sociales, la violence symbolique spécifiquement culturelle (la légitimité) s'est aussi accentuée, via les manières de consommer y compris des « objets » en apparence partagés. Nous ne discuterons donc pas plus avant l'éclectisme culturel dans cet article.

5. En français, pour des introductions à ce concept proposé par Kimberlé Williams Crenshaw en 1989, voir Crenshaw 2005 ; Dorlin 2009 ; Jaunait \& Chauvin 2012.

6. Sur l'identification du féminin aux stéréotypes de la féminité bourgeoise, et du masculin aux stéréotypes de la masculinité populaire, voir Bargel 2009.

7. Chaque indicateur est alors considéré comme l'une des expressions possibles d'un goût ou d'une position sociale.

8. Données diffusées par PROGEDO-ADISP (Production et gestion des données en sciences sociales-Archives de données issues de la statistique publique).

9. Le recours à l'AFM consolide ainsi l'interprétation en termes de domaines de goûts mais la modifie peu: l'ACM des goûts en matière de cinéma, de musique, de télévision et de lecture présente à peu de choses près les mêmes axes structurants, corrélés aux mêmes variables 
supplémentaires, et un nuage des individus similaire (graphiques disponibles auprès des auteurs).

10. Les Éditions Harlequin sont une maison d'édition spécialisée dans les romans d'amour.

11. Si l'analyse en est déployée dans Roueff \& Robette 2017, précisons ici que nous avons d'abord cherché d'autres qualificatifs ne connotant pas de position des modalités de goût dans les rapports sociaux de pouvoir avant même d'avoir testé leurs corrélations. Comme l'indiquent par exemple les termes exo/ésotérique, patrimonialisé/récent, hérö̈que/sentimental, cette tentative était vaine pour ne pas dire naïve. C'est qu'on échappe difficilement au codage de la culture par les rapports sociaux de pouvoir - nous y revenons en conclusion. On peut donc lire aussi ces qualifications comme des jugements sociaux relativement réalistes sur le goût des autres dans la logique relationnelle de La Distinction. En substance, le poète René Char est vu comme snob par les individus qui ne l'apprécient pas (et parfois par ceux qui l'apprécient), les films d'action comme vulgaires, virils et/ou juvéniles par ceux qui ne les apprécient pas (et parfois par ceux qui les apprécient), etc.

12. Pour des détails sur cette démarche, voir Robette \& Roueff 2014, 2017.

13. Le diplôme « explique » $32 \%$ de la variance de l'axe 1 , la catégorie socioprofessionnelle $30 \%$, le diplôme de la mère $16 \%$, de même que la catégorie socioprofessionnelle du père $16 \%$. L'âge « explique » $31 \%$ de la variance de l'axe 2 , et le sexe $10 \%$. Ces valeurs sont obtenues à partir du $\mathrm{R}^{2}$ de régressions linéaires réalisées avec les coordonnées sur l'axe en variable dépendante et la variable supplémentaire en variable indépendante (voir l'indicateur « eta ${ }^{2}$ » dans Le Roux \& Rouanet 2014).

14. Cette structure en $U$ peut a priori faire penser à un effet Guttman. Toutefois, ni le nuage des individus (voir figure 4) ni celui des variables actives (voir figure 2) ne présentent cette forme : les individus comme les variables actives sont dispersés dans une large partie du plan formé par les deux premiers axes. Ce sont bien spécifiquement les variables liées au volume des capitaux (diplôme et, dans une moindre mesure, catégorie socioprofessionnelle) qui ont cette forme en U. Par ailleurs, ce même U s'observe sur l'ACM combinant les quatre domaines de goût (cinéma, lecture, musique, télévision) comme sur les ACM réalisées pour chacun des domaines de goût (graphiques disponibles auprès des auteurs) : ceci confirme qu'il ne s'agit pas d'un artefact statistique dû à la technique de l'AFM.

15. De manière usuelle, on oppose les goûts snobs (ésotériques ou savants ; associés aux classes dominantes en particulier les plus diplômées) aux goûts vulgaires (exotériques ou "faciles d'accès "; associés aux classes populaires). Dans la même logique, on oppose les goûts anciens ou établis (apparus dans des états antérieurs du champ culturel et dont la consommation perdure aujourd'hui ; associés à des consommateurs âgés) aux goûts récents ou émergents (qui peuvent dater de périodes anciennes, comme la bande dessinée apparue au XIXe siècle, mais dont la visibilité en tant que genres est plus récente - les années 1960 pour la bande dessinée - et qui sont désormais associés à des consommateurs jeunes). On oppose enfin les goûts masculins (exprimant des valeurs socialement considérées comme masculines; associés à des consommateurs) aux goûts féminins (exprimant des valeurs socialement considérées comme féminines; associés à des consommatrices). Ces qualifications, simplificatrices et relatives par nécessité, n'apparaissent tautologiques que si l'on entretient l'illusion qu'un produit culturel existerait en soi, sous une forme "neutre", avant d'être saisi dans les rapports sociaux de pouvoir.

16. L'indice de corrélation choisi est le « résidu de Pearson ». Il est fondé sur le khi-deux mais, au lieu de donner une mesure globale du degré d'association entre deux variables, il calcule la surreprésentation de chaque croisement de modalités (ici, la variable classe croisée avec l'ensemble des variables actives et supplémentaires de l'AFM). Cette surreprésentation est généralement considérée comme significative si la valeur est supérieure à 1,96 mais, ce critère étant peu sélectif dans notre cas, nous distinguons les modalités dont le résidu est compris entre 
1,96 et 5 , celles dont le résidu est compris entre 5 et 10 et celles dont le résidu est supérieur à 10 . Par ailleurs, dans la logique d'exploration des interactions entre variables de position nous avons créé des variables combinant âge, sexe et diplôme soit deux à deux, soit les trois ensemble (nous les réutiliserons plus loin). Les résultats sont détaillés sous forme de tableaux en Annexe 2.

17. TF1 est la première chaine de télévision généraliste française en termes d'audience.

18. Stade 2 est un programme hebdomadaire d'information sportive.

19. Les feux de l'amour dont voici le générique.

20. Plus belle la vie est un feuilleton télévisé français relevant du Soap Opera.

21. Qui veut gagner des millions? est une adaptation française de Who Wants to be a Millionaire.

22. Des chiffres et des lettres est le jeu télévisé français le plus ancien. La première émission date du 4 janvier 1972.

23. Le plus grand cabaret du monde est une émission de télévision française diffusée le samedi soir entre le 26 décembre 1998 et le 4 mai 2019. L'émission alterne entre numéro de cabaret et discussions du présentateur avec les invités en promotion présentant leur dernière création.

24. France 3 est une chaîne de télévision généraliste française à vocation régionale.

25. Romans d'amour.

26. L'exploitation des questions portant sur le jeu vidéo ajouterait probablement à une telle analyse. $28 \%$ des personnes ayant utilisé un ordinateur au cours du dernier mois ont joué à des jeux vidéo. La variation est forte selon l'âge ( 3 fois plus de moins de 24 ans que de plus de 55 ans) et selon le sexe (37\% des hommes, $19 \%$ des femmes), relativement faible selon le diplôme mais sensiblement plus selon la catégorie socioprofessionnelle, au profit des ouvriers et des artisans, commerçants et chefs d'entreprise.

27. Pour une synthèse sur les loisirs et pratiques culturelles populaires, voir Siblot, Cartier, Coutant, Masclet, Renahy (2015).

28. Canal + est la principale chaine privée française consacrée aux séries, aux sports, aux films ainsi qu'aux émission de type «talk shows ».

29. Émission de télévision satirique française de marionnettes.

30. Émission française hebdomadaire de décryptage des médias.

31. Émission de télévision de documentaire belge, qui a pour but de traiter des sujets de société.

32. Violoniste jouant les hits de la musique classique à la télévision et dans de grandes salles de spectacle.

33. L'un des premiers auteurs de bande dessinée reconnu en France comme " artiste ».

34. Ceci peut tout autant renvoyer à un effet de structure (les plus âgée's sont moins diplômée's mais leurs diplômes sont plus distinctifs) qu'à d'autres effets : par exemple, ce ne sont peut-être pas les mêmes individus qui sont âgés et moins diplômés, bien qu'ils soient très corrélés par d'autres variables. Ce point dépasse le cadre de notre propos.

35. Une dernière piste a été suivie, à partir de modèles de régressions linéaires incluant des termes d'interaction entre diplôme, sexe et âge. Les résultats produits confirment ceux présentés ici et sont de ce fait renvoyés en Annexe 2.

36. On retrouve, pour chaque sexe, une "répartition en $U$ » des positions selon le niveau de diplôme.

37. On parle d'effet d'interaction, dans un modèle de régression linéaire, entre deux variables indépendantes $A$ et $B$ lorsque, par exemple, l'effet de la variable $A$ sur une troisième variable dépendante $\mathrm{C}$ change en fonction des valeurs de la variable indépendante $\mathrm{B}$. 


\section{RÉSUMÉS}

La notion de légitimité culturelle a connu de nombreuses déclinaisons et de nombreuses critiques. Pourtant, peu de travaux s'emploient à la construire de manière empirique et quantifiée à l'échelle d'un espace national et pour plusieurs pratiques culturelles. Malgré des débats théoriques intenses, une question demeure en particulier en jachère: l'échelle de légitimité culturelle étant définie par l'homologie entre l'ordonnancement des goûts et celui des groupes sociaux, de quel espace social est-il question? Nous proposons une démarche empirique pour tenir compte statistiquement de l'intersectionnalité des rapports sociaux de pouvoir, que de nombreuses enquêtes ethnographiques ont établie à l'échelle des individus et des groupes sociaux. Il s'agit essentiellement d'analyser les relations entre les variables de position sociale le diplôme, l'âge et le sexe, pour celles que nous retiendrons - sans tomber dans le piège improductif de la hiérarchisation des effets mais en les considérant plutôt en termes d'interactions. Nous établissons ainsi que, au niveau macro où se situe l'analyse, l'échelle de légitimité culturelle est associée simultanément aux trois rapports sociaux étudiés, opposant le bourgeois (lettré) au populaire, le féminin au masculin et l'ancien à l'émergent. Au final, l'échelle de légitimité est constituée de trois échelons principaux, associés à trois configurations de propriétés sociales : une culture lettrée, féminine et ancienne en « haut » de l'échelle, une culture lettrée, masculine et émergente au "milieu » et une culture populaire, féminine et ancienne en «bas ». L'interprétation sociologique permet ensuite de distinguer deux variations de la culture légitime, plus ou moins ancienne, féminine et lettrée, et trois variations de la culture illégitime en fonction des variables de sexe et d'âge : le goût pour les genres populaires "ringards » et «sentimentaux » se distingue du goût pour les produits « grand public » les plus accessibles par la radio, la télévision ou les magazines comme du goût pour les genres émergents et "virils » (science-fiction, rap ou hard rock...) qui sont parfois constitués en sous-cultures juvéniles et disponibles à des entreprises de légitimation. Au-delà de cette esquisse de typologie, nous cherchons surtout à établir l'existence de ces interactions, à proposer quelques outils statistiques utiles pour les étudier et à montrer l'intérêt qu'il y a à analyser la distribution des pratiques culturelles en termes intersectionnels.

The notion of cultural legitimacy has had many incarnations and been subject to many criticisms over the years. However, few studies have set out to construct it empirically and quantify it at the national level and over several cultural practices. In spite of the intense theoretical debates, one question remains particularly neglected - given that the scale of cultural legitimacy is defined by the homology between the ordering of tastes and the ordering of social groups, which social space does it actually refer to? Here we propose an empirical approach to statistically account for the intersection of social power relations which many ethnographic studies have observed at the level of individuals and social groups. The goal is to analyse the relations between variables related to social status; education, age, and gender are the ones we look at here. We avoid the unfruitful trap of simply constructing hierarchies of effects, and instead consider the interactions between them. We therefore observe that, at the macro level where our analysis is situated, the scale of cultural legitimacy is simultaneously associated with the three social relations studied, opposing bourgeois (intellectual) culture to popular culture, feminine culture to masculine culture, and established culture to new emerging culture. Ultimately, the scale of cultural legitimacy is made up of three main echelons, associated with three configurations of social characteristics: intellectual, feminine, and established at the "top" of the legitimacy scale, intellectual, masculine, and emerging at the "middle" and, finally, popular, feminine, and established, at the "bottom". A sociological interpretation allows us to distinguish 
two variations of legitimate culture that are more or less well established, feminine, and intellectual, and three variations of illegitimate culture depending on gender and age variables (a taste for "outdated" or "sentimental" working class genres, a preference for "mass public" products that are widely available on radio, television, or in magazines, and a taste for emerging "virile" genres (science-fiction, rap, hard rock, etc.), that are sometimes constituted as juvenile subcultures subject to processes of legitimation). Beyond this nascent typology, we seek above all to establish the existence of these interactions, to propose certain statistical tools that are useful for studying them and to demonstrate the benefit of analysing the distribution of cultural practices in intersectional terms.

\section{AUTEURS}

\section{CAMILLE NOÛS}

Laboratoire Cogitamus

\section{NICOLAS ROBETTE}

École nationale de la statistique et de l'administration économique (ENSAE)-Institut Polytechnique de Paris/Center for research in economics and statistics (Crest)

\section{OLIVIER ROUEFF}

CNRS/Centre de recherches sociologiques et politiques de Paris/Cultures et sociétés urbaines (Cresppa-CSU) 